\title{
Antilisterial and Antibiofilm Activities of Pediocin and LAP Functionalized Gold Nanoparticles
}

\author{
Atul K. Singh ${ }^{1 \dagger}$, Xingjian Bai ${ }^{1}$, Mary Anne Roshni Amalaradjou ${ }^{1 \dagger}$ and Arun K. Bhunia ${ }^{1,2 *}$ \\ ${ }^{1}$ Molecular Food Microbiology Laboratory, Department of Food Science, Purdue University, West Lafayette, IN, \\ United States, ${ }^{2}$ Department of Comparative Pathobiology, Purdue University, West Lafayette, IN, United States
}

In this study, we synthesized and assessed the antilisterial and antibiofilm properties of a novel gold nanocomposite, functionalized with antimicrobial peptide, Pediocin $\mathrm{AcH}$

\section{OPEN ACCESS}

Edited by:

Joshua B. Gurtler,

Agricultural Research Service (USDA),

United States

Reviewed by:

Dumitru Macarisin,

United States Food and Drug Administration, United States

Gregory Ross Siragusa,

Eurofins, United States

*Correspondence:

Arun K. Bhunia

bhunia@purdue.edu

${ }^{\dagger}$ Present Address

Atul K. Singh,

ClearLabs, Menlo Park, CA

United States

Mary Anne Roshni Amalaradjou,

Department of Animal Science, University of Connecticut, Storrs, CT, United States

Specialty section:

This article was submitted to

Agro-Food Safety,

a section of the journal

Frontiers in Sustainable Food Systems

Received: 12 June 2018

Accepted: 17 October 2018

Published: 16 November 2018

Citation:

Singh AK, Bai X, Amalaradjou MAR and Bhunia AK (2018) Antilisterial and

Antibiofilm Activities of Pediocin and LAP Functionalized Gold

Nanoparticles.

Front. Sustain. Food Syst. 2:74. doi: 10.3389/fsufs. 2018.00074 and Listeria adhesion protein (LAP) for targeted inactivation of L. monocytogenes. The gold nanoparticle (GNP) and the gold nanocomposites (GNP-Pediocin-LAP) were characterized using spectroscopic and transmission electron microscopy (TEM) and their effect on human enterocyte-like Caco-2 cells were assessed by lactate dehydrogenase (LDH)-based cytotoxicity and inhibition of Listeria adhesion assay. The antilisterial and antibiofilm activities of nanocomposites on $L$. monocytogenes were determined by a plating method. TEM image analysis indicated that the size of GNP and the gold nanoconjugates to be about 20 and $40 \mathrm{~nm}$, respectively; and spectroscopy indicated the successful loading of proteins onto citrate-stabilized GNPs. Gold nanocomposites were non-toxic and significantly reduced $L$. monocytogenes adhesion to Caco-2 cells. Relative to the GNP-Pediocin conjugate, the GNP-Pediocin-LAP conjugate showed $11.1 \%$ higher zone of inhibition in agar diffusion assay, and higher reduction $\left(1.5 \log _{10}\right.$ $\mathrm{CFU} / \mathrm{mL}$ ) in L. monocytogenes counts. Same preparation also showed 24 and $31 \%$ more reduction in Listeria counts in biofilms after 24 and $48 \mathrm{~h}$ of incubation, respectively. Nanocomposites were also highly effective in decontamination of $L$. monocytogenes on a miniature industrial conveyor system. Altogether, co-action of Pediocin and the LAP functionalized on GNP (GNP-Pediocin-LAP), demonstrated higher antilisterial and antibiofilm activities compared to the Pediocin functionalized GNP or Pediocin alone suggesting GNP can provide a platform to load multiple proteins for surface decontamination of $L$. monocytogenes in industrial settings.

Keywords: Listeria monocytogenes, pediocin, listeria adhesion protein (LAP), gold nanoparticle (GNP), biofilm, antimicrobial activity, bacteriocin, nanotechnology

\section{INTRODUCTION}

Gold nanoparticles (GNPs) offer a unique platform for multifaceted opportunity for the conjugation of biomolecules for diagnostic and therapeutic applications (Khlebtsov et al., 2013). GNPs offer inherent optical properties such as surface plasmon resonance (SPR) to monitor biomolecular interactions. GNPs conjugated with functional molecules have been used widely, such as colorimetric sensing of blood clotting enzyme, thrombin (Wei et al., 2007), drug delivery (Ghosh et al., 2008), cancer therapy (Peer et al., 2007), pathogen detection (Rossi et al., 2014; Weidemaier et al., 2015), and prostate cancer, and HIV protein detection 
(De La Rica and Stevens, 2012). GNP has been also used in the non-enzymatic electrochemical detection of sugars (Kurniawan et al., 2006) and active packaging in agri-food industry sector (Handford et al., 2014; Mihindukulasuriya and Lim, 2014). GNPs are desirable for biological application owing to their photostability, water solubility and nontoxicity (Kumar et al., 2008). Functionalization of GNPs for application in chemical and biological sensing has been thoroughly reviewed (Saha et al., 2012).

Synthesis of the gold colloidal solution was first reported by Michael Faraday in 1857 who mixed phosphorus with carbon disulfide to reduce auric chloride in water (Faraday, 1857). Later, the citrate-capped GNP was synthesized (Turkevich et al., 1951), where citrate has a dual role in reductive synthesis and stabilization of GNPs. In addition, GNP has been synthesized by other chemical and biological reducing agents, such as thiol (Brust et al., 1994), alpha-amylase (Rangnekar et al., 2007), plant leaf extracts (Song et al., 2009; Thakkar et al., 2010), bacteria (He et al., 2007; Thakkar et al., 2010), and fungi (Mukherjee et al., 2002). In this study, we made a smart gold nanoconjugate that is designed for targeted interaction with the bacteria of interest (Listeria monocytogenes) and inactivation by a bacteriocin, Pediocin.

Listeria monocytogenes is an opportunistic human foodborne pathogen that causes listeriosis in immunocompromised hosts including the elderly, neonates, unborn fetus and the patients suffering from viral or parasitic diseases or malignancies (Swaminathan and Gerner-Smidt, 2007). L. monocytogenes is found in soil, water, and sewage as a saprophyte, and in the intestines of cattle and sheep. The bacterium also persists in the food processing plants, forms biofilms and contaminates food products (Ferreira et al., 2014). Several methods have been used to inactivate biofilm forming cells including bacteriocins, bacteriophages, essential oils, and sanitizers (Gray et al., 2018), however, biofilms are recalcitrant to commonly used sanitization agents (Pan et al., 2006; Fu et al., 2017). In the United States, listeriosis has the third highest fatality rate (19\%) among the foodborne pathogens (Scallan et al., 2011), and globally, the estimated perinatal infection rate is $20.7 \%$ (De Noordhout et al., 2014; Jordan and Mcauliffe, 2018). Listeria outbreaks are often associated with ready-to-eat (RTE) products including deli meats, hotdogs, liver pâté, and smoked fish, soft cheeses prepared from unpasteurized milk, ice cream and produce such as vegetables, mung bean sprout, celery cantaloupe, and apple (Buchanan et al., 2017). The 2011 outbreak of listeriosis from cantaloupes in Colorado (USA) resulted in 147 cases and 33 deaths, making it the deadliest recorded US foodborne outbreak (Mccollum et al., 2013). In 2018, the largest outbreak of listeriosis is reported in South Africa, with 1,056 cases and 215 deaths involving a sausage product, Polony (Allam et al., 2018) (http://www.nicd.ac.za/

Abbreviations: GNP, gold nanoparticle; PBS, phosphate buffered saline; BHI, brain heart infusion; BHIA, brain-heart infusion agar; MOX, modified-Oxford agar; Ped, Pediocin; LAP, Listeria adhesion protein; LDH, lactate dehydrogenase; Lm, Listeria monocytogenes; SPR, surface plasmon resonance. index.php/listeriosis-outbreak-situation-report-_4july2018/). The estimated infectious dose of L. monocytogenes is $10^{6}-10^{7}$ CFU in primates and susceptible humans (Farber et al., 1996; Smith et al., 2008). However, in the 2015 ice cream outbreak, the FDA estimated that $99.8 \%$ of ice cream samples contained $<100 \mathrm{MPN} / \mathrm{g}$, thus implying a very low infectious dose for this pathogen (Chen et al., 2016; Pouillot et al., 2016; Buchanan et al., 2017). In the US, there is a "zero tolerance" policy for L. monocytogenes in RTE products, i.e., 0 cells in $5 \times 25 \mathrm{~g}$ samples. Food industry loses millions of dollars due to Listeria associated food outbreaks. The annual cost of the outbreak is about $\$ 2$ billion and financial losses due to a single recall have been estimated to range between $\$ 0.16$ and $\$ 0.3$ million (Ivanek et al., 2005). As indicated above, Listeria spp. persist in the food-processing environment often as biofilms and are responsible for post-processing contamination of RTE foods (Bonsaglia et al., 2014; Galié et al., 2018; Gray et al., 2018). Therefore, Listeria testing primarily involves monitoring of environmental samples and there is a critical need for improved L. monocytogenes control in the food production/processing environment.

In this study, we synthesized citrate-capped GNPs and functionalized these particles with the Listeria adhesion protein (LAP) (Pandiripally et al., 1999; Jagadeesan et al., 2010) as a ligand for L. monocytogenes interaction, and Pediocin $\mathrm{AcH}$ (Bhunia et al., 1988) for targeted inactivation of Listeria cells in biofilm and (or) in planktonic state in simulated food production facilities. Pediocin $\mathrm{AcH}$ is an antimicrobial peptide of $\sim 4 \mathrm{kDa}$ and is produced by Pediococcus acidilactici strain $\mathrm{H}$, a food-fermenting lactic acid bacterium (Bhunia et al., 1988). Pediocin is active against Gram-positive bacteria including $L$. monocytogenes and induces membrane pore formation (Bhunia et al., 1991).

LAP was used for targeted interaction of GNP-Pediocin complex on L. monocytogenes cells. LAP is an epithelial cell adhesion factor of L. monocytogenes that interacts with the host heat shock protein 60 (Hsp60) (Wampler et al., 2004; Burkholder and Bhunia, 2010; Jagadeesan et al., 2011) and induces intestinal epithelial barrier dysfunction allowing L. monocytogenes passage across the gut barrier during the intestinal phase of infection (Drolia et al., 2018). LAP, an alcohol acetaldehyde dehydrogenase (a housekeeping enzyme) is secreted from L. monocytogenes by the SecA2 pathway and it re-associates on the surface of the bacterium (Burkholder et al., 2009; Jagadeesan et al., 2010). Even though the nonpathogenic Listeria spp. synthesize and secrete LAP, it's re-association on the surface of producing cell is modest (Burkholder et al., 2009; Jagadeesan et al., 2010).

We hypothesize that functionalization of GNP-Pediocin nanoconjugate with the LAP molecule will enhance the antilisterial activity owing to its specificity and targeted association with the Listeria cells. In this study, this hypothesis was verified by synthesizing GNP, followed by sequential functionalization with Pediocin and LAP and tested against $L$. monocytogenes in biofilms or in the planktonic state on the agar plate or on a miniature operational industrial conveyor system. 


\section{MATERIALS AND METHODS}

\section{Bacterial Strains and Growth Conditions}

Bacterial strains used in this study and their details are provided in Table 1. Listeria cultures were used as indicator strains to assess the effect of Pediocin AcH produced by Pediococcus acidilactici strain $\mathrm{H}$ (Bhunia et al., 1988). P. acidilactici was grown in de Man, Rogosa and Sharpe (MRS) broth at $37^{\circ} \mathrm{C}$ for $16 \mathrm{~h}$ under static condition. All cultures were stored as $10 \%$ frozen glycerol stocks at $-80^{\circ} \mathrm{C}$. Prior to experiments, frozen bacterial stocks were streaked on brain heart infusion (BHI, Acumedia, Neogen, Lansing, MI) agar and incubated at $37^{\circ} \mathrm{C}$ for $16-18 \mathrm{~h}$ to obtain a single colony. Single Listeria colony was propagated in $\mathrm{BHI}$ broth at $37^{\circ} \mathrm{C}$ for $16 \mathrm{~h}$. For selective enumeration of the Listeria spp., cultures were also plated on modified Oxford (MOX) agar containing filter-sterilized moxalactam $(20 \mathrm{mg} / \mathrm{L})$ and colistin sulfate $(10 \mathrm{mg} / \mathrm{L})$ (Acumedia). Listeria cultures were spread-plated on BHI agar plate after (10-fold) serial dilutions of bacteria in phosphate-buffered saline (PBS, pH 7.4). BHI agar plates were incubated at $37^{\circ} \mathrm{C}$ for $16 \mathrm{~h}$, and MOX agar plates wrapped in a plastic bag were incubated at $37^{\circ} \mathrm{C}$ for $24-48 \mathrm{~h}$ before enumeration.

\section{Purification of LAP and Pediocin}

Recombinant LAP was purified from E. coli BL21 (DE3) carrying expression vector pET32a-LAP (Kim et al., 2006; Jagadeesan et al., 2011). Briefly, recombinant LAP expressing E. coli BL21 (DE3) was grown in $500 \mathrm{~mL} \mathrm{LB}$ broth supplement with $50 \mu \mathrm{g} / \mathrm{mL}$ ampicillin. Expression of recombinant LAP in host E. coli strain grown at $37^{\circ} \mathrm{C}$ for $4 \mathrm{~h}$ or until $\mathrm{OD}_{600}$ reached 0.4 was induced with $0.2 \mathrm{mM}$ IPTG (Sigma Aldrich) at $25^{\circ} \mathrm{C}$ for $10 \mathrm{~h}$. Cultures were centrifuged $(10,000 \mathrm{~g}, 10 \mathrm{~min})$ and the cell pellet was stored at $-80^{\circ} \mathrm{C}$ overnight in $1 \mathrm{X}$ binding buffer of His-Bind purification kit (EMD Chemicals, Gibbstown, NJ). The cell pellet was thawed and lysed by sonication ( 5 cycles, $30 \mathrm{~s}$ each cycle on ice; Branson Sonifier, Danbury, CT) and centrifuged $(16000 \times \mathrm{g}, 15 \mathrm{~min})$ to discard the cellular debris and collect the supernatant containing intracellular proteins. Recombinant histidine-tagged LAP was purified by affinity chromatography using the HisTrap ${ }^{\mathrm{TM}}$, HP prepacked columns (GE Healthcare) and His-Bind resin kit following manufacturers instruction (EMD Chemicals). Elutes from Ni-column were dialyzed using $12-\mathrm{kDa}$ MWCO dialysis bag (Millipore, Billerica, MA) and protein concentration was quantified by using bicinchoninic acid (BCA) method (Pierce, Rockford, IL). The concentration of purified LAP was 1.29 $\mathrm{mg} / \mathrm{mL}$ and the LAP purity was assessed by SDS-PAGE $(7.5 \%$ acrylamide gel) and Western blot using anti-LAP antibody (mAb-H7) (Kim et al., 2006).

Pediocin AcH was purified from $P$. acidilactici strain $\mathrm{H}$ (Bhunia et al., 1988) by following a cell adsorption method (Yang et al., 1992). A single colony of $P$. acidilactici strain $\mathrm{H}$ was inoculated into $10 \mathrm{~mL}$ MRS broth and incubated at $37^{\circ} \mathrm{C}$ for $18 \mathrm{~h}$ under static condition. This culture was used to inoculate $1 \mathrm{~L}$ of MRS broth and incubated under the same condition for the adsorption-based purification of Pediocin AcH. The $\mathrm{pH}$ of overnight grown culture was 3.5 and was adjusted to 6.5 with $1 \mathrm{~N}$ $\mathrm{NaOH}$ before heat-inactivation of Pediococcus at $70^{\circ} \mathrm{C}$ for $25 \mathrm{~min}$ with continuous stirring. The culture broth was centrifuged at $12,857 \times \mathrm{g}$ for $10 \mathrm{~min}$ to harvest the Pediococcus cells with adsorbed Pediocin AcH molecules. The cell pellet was washed with $5 \mathrm{M}$ sodium phosphate buffer ( $\mathrm{pH}$ 6.5). The cell pellet was resuspended in $20 \mathrm{~mL}$ of $100 \mathrm{mM} \mathrm{NaCl}$ at $\mathrm{pH} 2$ adjusted with $5 \%$ phosphoric acid and mixed with a magnetic stirrer for $1 \mathrm{~h}$ at $4^{\circ} \mathrm{C}$. The cell suspension was centrifuged at $12,857 \times \mathrm{g}$ for $20 \mathrm{~min}$ and the supernatant containing Pediocin $\mathrm{AcH}$ was collected. The supernatant was dialyzed against sterile molecular grade water using $1 \mathrm{kDa}$ molecular weight cut-off dialysis bag (Sigma Aldrich). A stock solution of dialyzed Pediocin was quantified $(0.52 \mathrm{mg} / \mathrm{mL})$ and lyophilized for a long-term storage. Activity unit (AU) of purified Pediocin was measured by a spot-on-lawn assay against $L$. monocytogenes F4244 (an epidemic strain, 4b serotype) and determined to be $25,600 \mathrm{AU} / \mathrm{mL}$ (Bhunia et al., 1988). For the spot-on-lawn assay, $20 \mu \mathrm{L}$ of 7 -h grown culture of Listeria spp. was added to $7 \mathrm{~mL}$ sterile $\mathrm{BHI}$ soft-agar $(0.8 \%$ agar) and this was poured on the regular BHI agar plates and allowed to solidify in a biosafety cabinet for $5 \mathrm{~min}$. Thereafter, 10 $\mu \mathrm{L}$ preparation of double-dilutions of Pediocin preparation was spotted on the lawn seeded with Listeria cells, incubated at $4{ }^{\circ} \mathrm{C}$ for $10 \mathrm{~min}$ for the adsorption of the spotted pediocin, and incubated at $37^{\circ} \mathrm{C}$ for $18 \mathrm{~h}$ to observe the zone of inhibition, $\mathrm{ZOI}(\geq 0.2 \mathrm{~mm}$ radius). Activity unit $(\mathrm{AU} / \mathrm{mL})=$ highest dilution showing $\mathrm{ZOI}$ $x$ dilution factor for the Pediocin volume spotted on the agar plate.

\section{Synthesis of GNPs and Functionalization of GNPs With Pediocin and LAP}

The citrate-stabilized gold nanoparticles (GNPs) were synthesized as described before (Kumar et al., 2008). Briefly, to prepare $50 \mathrm{~mL}$ of negatively charged GNP ( $20 \mathrm{~nm}$ size), a volume of $0.5 \mathrm{~mL}$ of $1 \% \mathrm{HAuCl}_{4}$ solution (Salt Lake Metals, Utah) was added in the $49.5 \mathrm{~mL}$ of deionized ultrapure water (18 $\mathrm{M} \Omega \cdot \mathrm{cm})$ and boiled for $1 \mathrm{~min}$. Thereafter, $0.94 \mathrm{~mL}$ of $38.8 \mathrm{mM}$ trisodium citrate solution was added and boiled for $5 \mathrm{~min}$ with continuous stirring. The color of the synthesized GNP solution appeared red and the $\mathrm{pH}$ was 5.5. GNP colloidal solution was scanned with the ultraviolet-visible (UV-vis) spectroscopy using DU800 spectrophotometer (Beckman Coulter) from 400 to $700 \mathrm{~nm}$, and a surface plasmon resonance (SPR) peak at $524 \mathrm{~nm}\left(\mathrm{~A}_{\mathrm{spr}}\right)$ was measured. Uncapped/uncoated GNP size and concentration were also measured by calculating the ratio of absorbance at $524 \mathrm{~nm}$ and $450 \mathrm{~nm}$, and the ratio of absorbance and molar decadic extinction coefficient $\left(\mathrm{A}_{450} / \varepsilon_{450}\right)$, respectively based on the reference tabular data from a previously published article (Haiss et al., 2007). Stability and synthesis of well-isolated GNP (red color) was measured as a ratio (R) of absorbance at $524 \mathrm{~nm}\left(\mathrm{~A}_{\mathrm{spr}}\right)$ and $600 \mathrm{~nm}$, whereas interaction of GNP and Pediocin $(0,0.21,0.42,0.84$, and $1.56 \mu \mathrm{g} / \mathrm{mL})$ which changed the color of GNP from red to violet due to the binding of Pediocin to GNP and aggregation of GNP was measured as a ratio of absorbance at $600 \mathrm{~nm}$ and surface plasmon resonance absorbance peak at $524 \mathrm{~nm}$. Therefore, the interaction of GNP with Pediocin was assessed qualitatively by monitoring color change and quantitatively by measuring the ratio of absorbance 
TABLE 1 | Bacterial strains used in this study.

\begin{tabular}{|c|c|c|c|}
\hline Bacteria & Strain (source) & Origin/outbreak & Reference \\
\hline L. monocytogenes & F4244 & CDC; Human CSF/lce cream & Schwartz et al., 1989 \\
\hline L. ivanovii & ATCC 19119 & Sheep, Bulgaria & Seeliger et al., 1984 \\
\hline L. welshimeri & ATCC 35897 & Decaying plant material & Rocourt and Grimont, 1983 \\
\hline L. innocua & F4248 & CDC & CDC \\
\hline L. marthii & BAA 1595 & Soil, Finger Lakes National Forest, NY & Graves et al., 2010 \\
\hline L. grayi & ATCC 19120 & Animal feces & Larsen and Seeliger, 1966; Rocourt et al., 1992 \\
\hline Pediococcus acidilactici & $\mathrm{AcH}$ & Fermented sausage & Bhunia et al., 1988 \\
\hline
\end{tabular}

at $600 \mathrm{~nm}$ and $524 \mathrm{~nm}$. Purified Pediocin AcH and LAP were added to the GNP at the respective concentration of $1.25 \mu \mathrm{g} / \mathrm{mL}$ and $10 \mu \mathrm{g} / \mathrm{mL}$ separately for overnight at room temperature to produce GNP-Pediocin and GNP-LAP nanoconjugates. GNP-Pediocin-LAP nanoconjugates were made by adding both Pediocin and LAP together to the GNP solution at the same concentration. These nanoconjugates were centrifuged at $14,000 \mathrm{rpm}$ at $4^{\circ} \mathrm{C}$ for $20 \mathrm{~min}$ (Eppendorf Centrifuge) and washed once with PBS to remove unbound Pediocin and LAP. The nanoconjugates were finally resuspended in PBS and characterized by UV/Vis spectroscopy and transmission electron microscopy (TEM) (see below). The final protein concentration loaded onto the gold nanoconjugates was calculated to be $1 \mu \mathrm{g} / \mathrm{mL}$ for Pediocin and $8.2 \mu \mathrm{g} / \mathrm{mL}$ for LAP.

\section{Characterization of Gold Nanoparticles and Nanoconjugates}

To assess the electrostatic interactions between negatively charged citrate-stabilized GNP and positively charged Pediocin peptide, UV-visible spectra were acquired over the range of $400-800 \mathrm{~nm}$. The $\mathrm{pH}$ of GNP was adjusted to 7 and 10 , and a 990- $\mu \mathrm{L}$ aliquot GNP interacted with $10 \mu \mathrm{L}$ Pediocin (diluted stock conc. $80 \mu \mathrm{g} / \mathrm{mL}$ ). Additionally, TEM was used to determine the size distribution of GNP. GNP and GNP-Pediocin samples were allowed to dry on carbon-coated 400 -mesh $\mathrm{Cu}$ grid. A $2 \%$ uranyl acetate was used to fix GNP-Pediocin nanoconjugates. All samples were allowed to settle on the grid before drying. TEM images were captured using a Philips CM-100 TEM microscope (FEI Company, Hillsboro, OR) operated at $100 \mathrm{kV}$, spot 3,200 $\mu \mathrm{m}$ condenser aperture and $70 \mu \mathrm{m}$ objective aperture. Images were captured on Kodak SO-163 electron image film.

\section{Protein Functionalized GNP and Antilisterial Activity Assessment}

TEM was performed to assess the interaction of GNPPediocin nanoconjugate to L. monocytogenes F4244 cells. Gold nanoconjugate-treated bacterial cells were fixed in 5\% glutaraldehyde fixative solution diluted to $1: 1$ ratio with the $\mathrm{BHI}$ broth. The cells were examined under an FEI/Philips CM-10 transmission electron microscope as described above.

Western blotting and bacterial growth inhibition assay were used to determine protein loading in GNP-LAP, GNPPediocin, and GNP-Pediocin-LAP. About $10 \mu \mathrm{g}$ of purified LAP was allowed to interact with GNP and GNP-Pediocin overnight and loading was quantified by immunoblot assay. First, the nanoconjugates were directly loaded into the well of an SDS-PAGE gel (7.5\% acrylamide) and electrophoresed in a Criterion cell system (Bio-Rad, Hercules, CA). Proteins were then transferred to an Immobilon-P membrane (Millipore) by using a Criterion blotter (Bio-Rad). The membranes were blocked with blocking buffer [5\% non-fat skim milk (NFSM) and PBST, PBS plus $0.2 \%$ Tween 20] for $2 \mathrm{~h}$ at room temperature. The membranes were probed with LAP-specific mAb (Em10) diluted $1: 1,000$ at $4^{\circ} \mathrm{C}$ for $18 \mathrm{~h}$ in a blocking buffer. HRP-conjugated anti-mouse antibody (Jackson Immuno Research) was used at 1:2,000 dilution for 1 to $1.5 \mathrm{~h}$ and washed thrice with PBST for 5 to $10 \mathrm{~min}$ at room temperature and developed using Pierce enhanced chemiluminescence substrate (Thermo Scientific) on X-ray film (Jagadeesan et al., 2010).

To verify the contribution of LAP in the enhanced antilisterial activity of GNP-Ped, LAP-specific mAb (mAb-H7) was used to block the conjugated LAP molecules. Briefly, mAb-H7 $(1 \mu \mathrm{g} / \mathrm{ml})$ was added to GNP-Pediocin-LAP at $37^{\circ} \mathrm{C}$ for $20 \mathrm{~min}$ and $20 \mu \mathrm{l}$ of the mixture was tested in a well-diffusion assay against the lawn of L. monocytogenes cells (see below). Plates were incubated at $37^{\circ} \mathrm{C}$ for $18-24 \mathrm{~h}$ and diameter of the inhibition zone was measured.

Amount of Pediocin loaded on the nanoparticles was quantified using an agar well diffusion assay to kill Listeria cells on the agar lawn. Briefly, Petri plates containing BHI agar (1.5\% agar) were overlaid with sterile BHI soft agar $(0.8 \%)$ seeded with $20 \mu \mathrm{L}$ of freshly $(8 \mathrm{~h})$ grown L. monocytogenes F4244 cells. Wells of $7.0 \mathrm{~mm}$ diameter were dug with a cork borer and $50 \mu \mathrm{L}$ of different dilutions of Pediocin preparations were dispensed per well. Plates were held at $4^{\circ} \mathrm{C}$ for $15 \mathrm{~min}$ for absorption of test samples and incubated at $37^{\circ} \mathrm{C}$ for $18-24 \mathrm{~h}$ to observe zone of inhibitions (ZOI) around the wells.

A standard curve based on the diameter of ZOI (y-axis) and different concentrations of unconjugated Pediocin (1.05, $0.52,0.26,0.13,0.07,0.03 \mu \mathrm{g} / \mathrm{mL})$ was generated on the lawn of L. monocytogenes cells. In another well, $50 \mu \mathrm{L}$ of GNPPediocin solution, which was prepared by interacting $1.25 \mu \mathrm{g} / \mathrm{mL}$ of purified Pediocin was also loaded and inhibition zone was quantified to assess the amount of Pediocin loaded to the GNPPediocin nanoconjugate. Amount of Pediocin loaded on the GNP was quantified by matching the inhibition zone with the ZOI generated with the unconjugated free Pediocin. 


\section{Nanoconjugate-Mediated Cytotoxicity Analysis on Caco-2 Cells}

The human colon adenocarcinoma cell line, Caco-2 (ATCC, Manassas, VA) was cultured in Dulbecco's' Modified Eagles' Medium (DMEM with high glucose from HyClone ${ }^{\mathrm{TM}}$, GE, Logan, Utah) with $10 \%$ (vol/vol) fetal bovine serum (FBS, Atlanta Biologicals, GA) at $37^{\circ} \mathrm{C}$ with $7 \% \mathrm{CO}_{2}$ in a humidified cell culture incubator (Burkholder et al., 2009). Polystyrene 24-well tissue culture plates (Corning Life Sciences, NY) were seeded with approximately $5 \times 10^{4}$ cells and were grown at least for 12 days or until differentiated, and cell culture medium was changed twice a week. Cytotoxic effect of GNP and its derivatives on Caco- 2 cells was measured as a function of lactate dehydrogenase (LDH) release (Roberts et al., 2001) using a cytotoxicity assay kit (Thermo Scientific, Frederick, MD). Confluent Caco-2 cells in 24 wells were treated with Pediocin and LAP (each $1 \mu \mathrm{g} / \mathrm{mL}$ ); GNP (1.5 nM); GNP-Pediocin $(1.0 \mu \mathrm{g} / \mathrm{mL})$, GNP-LAP $(7.7 \mu \mathrm{g} / \mathrm{mL})$, GNP-Pediocin-LAP $(8.2 \mu \mathrm{g} / \mathrm{mL})$, and L. monocytogenes $\left(10^{6}\right.$ $\mathrm{CFU} / \mathrm{mL}$ ) as positive control for $2 \mathrm{~h}$ at $37^{\circ} \mathrm{C}$ with $7 \% \mathrm{CO}_{2}$ in a humidified cell culture incubator. DMEM alone and DMEM containing $1 \%$ Triton X-100 were used as low and high controls, respectively. The supernatants collected after treatment were used to measure LDH activity (Koo et al., 2012). Since Listeria colonization results in cell-mediated cytotoxicity in the intestinal epithelial cells, the ability of GNP and nanoconjugates to protect the monolayers from $L$. monocytogenes-induced cytotoxicity was assayed. The experiment was set up as described above. Briefly, Caco-2 monolayers were pre-exposed to the different treatments for $1 \mathrm{~h}$ and then infected with Listeria (MOI, 10) for $1 \mathrm{~h}$. Supernatants collected after treatment were used to measure $\mathrm{LDH}$ activity in a 96-well microtiter plate from two independent experiments with three technical replicates for each experiment. We used the following equation to calculate cytotoxicity, where the exp. value represents the treatment of Caco-2 cells with GNP conjugates and biomolecules, low control represents the treatment of Caco- 2 cells with DMEM alone (negative control), and the high control represents treatment with $1 \%$ Triton X-100 (positive control).

$$
\% \text { Cytotoxicity }=\left[\frac{\text { Exp. value }- \text { Low control }}{\text { High control }- \text { Low control }}\right] X 100
$$

The data were plotted as a mean of percent cytotoxicity \pm standard error of the mean (SEM) and analyzed using the GraphPad Prism version 6.0.

\section{Nanoconjugate-Mediated Inhibition of $L$. monocytogenes Adhesion to Caco-2 Cells}

To study the inhibition of $L$. monocytogenes adhesion to Caco-2 cell monolayers by the gold nanoconjugates, Caco2 cells were pretreated with the same concentrations of nanoconjugates as above for $2 \mathrm{~h}$ before $L$. monocytogenes inoculation. Monolayers were washed thrice with DMEM and infected with L. monocytogenes at an MOI of $10 \quad(\sim 6$ $\log \mathrm{CFU} /$ well) for $1 \mathrm{~h}$ at $37^{\circ} \mathrm{C}$. The infected monolayers were rinsed three times with $\mathrm{PBS}$ and cells were lysed with $0.1 \%$ Triton $\mathrm{X}-100$. The number of viable adherent
L. monocytogenes was determined by serial dilution and plating on BHI agar plates as before (Burkholder et al., 2009).

\section{Analysis of Antibiofilm Activity of Gold Nanoconjugates \\ Inhibition of Listeria Biofilm Formation}

The efficacy of GNPs in inhibiting Listeria biofilm formation was performed as before (Amalaradjou and Venkitanarayanan, 2014). Briefly, L. monocytogenes F4244 was grown overnight in $\mathrm{BHI}$ at $37^{\circ} \mathrm{C}$, sedimented by centrifugation $(3,600 \times \mathrm{g}$ for $15 \mathrm{~min}$ ), washed twice with PBS and resuspended in $10 \mathrm{~mL} \mathrm{BHI}$ broth. Sterile 96-well polystyrene tissue culture plates (Falcon, Franklin Lakes, NJ) were inoculated with $200 \mu \mathrm{L}$ of bacterial suspension $(\sim 6.0 \log \mathrm{CFU})$, followed by the addition of GNP (1.5 nM), Pediocin $(1 \mu \mathrm{g} / \mathrm{mL})$ only, GNP-Pediocin $(1.0 \mu \mathrm{g} / \mathrm{mL})$, GNP-LAP $(7.7 \mu \mathrm{g} / \mathrm{mL})$, or GNP-Pediocin-LAP $(8.2 \mu \mathrm{g} / \mathrm{mL})$ and incubated at $37^{\circ} \mathrm{C}$. At 24 and $48 \mathrm{~h}$ post inoculation, the wells were washed three times with PBS, and the adherent biofilms were scraped off using a metal spatula (Finelli et al., 2003) and plated directly or after a serial dilution in PBS on BHI agar plates. The plates were incubated at $37^{\circ} \mathrm{C}$ for $24-48 \mathrm{~h}$ and colonies were counted. A set of wells inoculated with Listeria without any treatment were used as the controls. Triplicate samples were included for each treatment, and the experiment was repeated three times.

\section{Inactivation of Pre-formed Listeria Biofilms}

Similarly, for inactivation of preformed biofilms by gold nanoconjugates, sterile 96-well polystyrene Costar tissue culture plates were inoculated with $200 \mu \mathrm{L}$ of bacterial suspension (about $6.0 \log _{10} \mathrm{CFU}$ ) and incubated at $37^{\circ} \mathrm{C}$ for $24 \mathrm{~h}$ without agitation to allow biofilm formation. The wells were washed 3 times with $200 \mu \mathrm{L}$ of sterile PBS to remove unattached bacteria, and treated with Pediocin, and GNP or its derivatives as above for 24 and $48 \mathrm{~h}$ at $37^{\circ} \mathrm{C}$. The biofilm-forming L. monocytogenes cells were scraped off from the wells of microtiter plates with a sterile steel spatula, serially diluted in PBS and plated on BHI agar for bacterial enumeration. Three replicate wells for each treatment were included and the assay was repeated 3 times.

\section{Inactivation of L. monocytogenes on a Conveyor System}

To mimic the industrial surface decontamination/inactivation process the following experiments were performed. Nonselective BHI and Listeria-selective MOX agar Petri-plates were first contaminated by spraying with $100 \mu \mathrm{L}(1.5 \pm 0.5 \times$ $\left.10^{2} \mathrm{CFU}\right)$ of $L$. monocytogenes cells. A bottle sprayer $(65 \mathrm{~mL})$ containing $10 \mathrm{~mL}$ of diluted cells $\left(1.5 \pm 0.5 \times 10^{3} \mathrm{CFU} / \mathrm{mL}\right)$ was used to spray approximately $100 \mu \mathrm{L}$ of Listeria cells on the agar plates and held at room temperature for 10 min inside a Class II biosafety cabinet. GNP-Pediocin-LAP nanocomposite solution was sprayed on the plates in a similar fashion and again held at room temperature for $10 \mathrm{~min}$ inside the biosafety cabinet. As a control, PBS was used. Agar plates were incubated at $37^{\circ} \mathrm{C}$ for $24 \mathrm{~h}$, and colonies were enumerated. 
In another experiment, an operational miniature conveyor system (Shuttleworth, Huntington, IN) was used to assess the deactivation potential of GNP-Pediocin-LAP conjugate on the equipment surface. The conveyor was placed inside a stainless-steel tray, which was previously sanitized using $1 \%$ bleach (Clorox), followed by $70 \%$ ethanol and subsequent washing with sterile water and the entire system was kept inside a Class II Biosafety cabinet. The entire conveyor including the moving parts was pre-inoculated with $10 \mathrm{~mL}$ of L. monocytogenes $\left(10^{6} \mathrm{CFU} / \mathrm{mL}\right.$ of PBS) using a spray bottle and held at room temperature for $1 \mathrm{~h}$. The swab samples were collected from 13 marked locations (see Table 2) from the conveyor and the data were recorded under the untreated category. For treated category, Listeria cells were again sprayed on the conveyor system and after $30 \mathrm{~min}$, $10 \mathrm{~mL}$ of GNP-Pediocin-LAP conjugate was sprayed on the conveyor system and held for $1 \mathrm{~h}$ before sampling. Prewet swabs were used to collect samples from 13 marked locations on the conveyor system and Listeria growth was monitored in Fraser broth (FB) at $37^{\circ} \mathrm{C}$ for $24 \mathrm{~h}$. A sample was considered positive for Listeria when FB turned black.

\section{Statistical Analysis}

Statistical analyses were performed using one-way analysis of variance (ANOVA) with Tukey's multiple comparisons test (GraphPad Prism, version 6.0) to measure significant differences $(P<0.05)$ with high individual scores to compare antilisterial, cytotoxicity, adhesion, and antibiofilm activities of gold nanoconjugates. ImageJ, an image analysis software (Schneider et al., 2012) was used to measure the diameter of GNP/nanoconjugates and quantify the immunoblot protein bands.

\section{RESULTS}

\section{Characterization of GNP and Gold Nanoconjugates}

The citrate-stabilized negatively charged GNP revealed a bright red color and was found to be stable at room temperature. Its color changed to violet with increasing concentrations of Pediocin $\mathrm{AcH}$, demonstrating the interaction of GNP and Pediocin (Figure 1A). The ratio of SPR absorbance peak at $524 \mathrm{~nm}$ and the absorbance at $600 \mathrm{~nm}$ that measures stability and synthesis of well isolated GNP (red color) was 4.4, which is close to R-value of $\sim 3.5-4$ representing stable and well isolated GNPs (Haiss et al., 2007). However, the R-values of GNP conjugated with purified Pediocin decreased to 1.98, 1.20, 0.93 and 0.92 , with increasing concentrations of Pediocin (0.21, $0.42,0.84$, and $1.68 \mu \mathrm{g} / \mathrm{mL}$ ), respectively. Similarly, the ratio of $\mathrm{A}_{600} / \mathrm{A}_{524}$ increased from 0.23 to 1.09 with increasing concentration of Pediocin from $0 \mu \mathrm{g} / \mathrm{mL}$ to $1.68 \mu \mathrm{g} / \mathrm{mL}$, which represent a higher number of GNP nanoconjugates (Figure 1B).

Additional evidence for the interactions of GNPs with Pediocin and LAP were obtained from TEM photomicrographs. Measurement of single GNP and GNP conjugates using ImageJ program revealed an increase in size from about $20 \mathrm{~nm}$ for GNP to about $40 \mathrm{~nm}$ for GNP-Pediocin nanoconjugate (Figures 1C,D). After comparing the UV-vis spectral data with the reference table in the literature (Haiss et al., 2007), the ratio of $\mathrm{A}_{524} / \mathrm{A}_{450}$ was 1.79 , which corresponds to $20-25 \mathrm{~nm}$ diameter of GNP that matches the size calculated by TEM imaging (Figure 1B). Similarly, the concentration of GNP was found to be $1.5 \mathrm{nM}$ based on the calculated ratio of $\mathrm{A}_{450} / \varepsilon_{450}$ for the $20 \mathrm{~nm}$ size GNP.

Furthermore, we also quantified the SPR signal by UV-vis spectroscopy to confirm the electrostatic interaction between

TABLE 2 | Surface decontamination of an operational conveyor model system using GNP-Ped-LAP conjugate.

\begin{tabular}{llcc}
\hline Sample No. & Location on conveyor & $\begin{array}{c}\text { Growth in fraser broth before } \\
\text { treatment with GNP-Ped-LAP } \\
\text { conjugate }\end{array}$ & $\begin{array}{c}\text { Growth in Fraser broth after } \\
\text { treatment with GNP-Ped-LAP } \\
\text { conjugate }\end{array}$ \\
\hline 1. & Underneath closed bushing & - & - \\
2. & Inside closed bushing & - & - \\
3. & Underneath open bushing & + & - \\
4. & Inside open bushing & - & - \\
5. & Inside loose bushing & - & - \\
6. & Inside tight rings & + & - \\
7. & Rods & - & - \\
8. & Spokes of the gear & - & - \\
9. & Small chain (left) & + & - \\
10. & Small chain (right) & - & - \\
11. & Big chain & - & - \\
12. & Tight stoppers & - & - \\
13. & Plastic chain support & - & \\
\hline
\end{tabular}

+, indicate growth of Listeria; -, indicate no growth of Listeria in Fraser broth (Listeria selective enrichment broth). GNP, gold nanoparticle; Ped, Pediocin AcH; LAP, Listeria adhesion protein. 

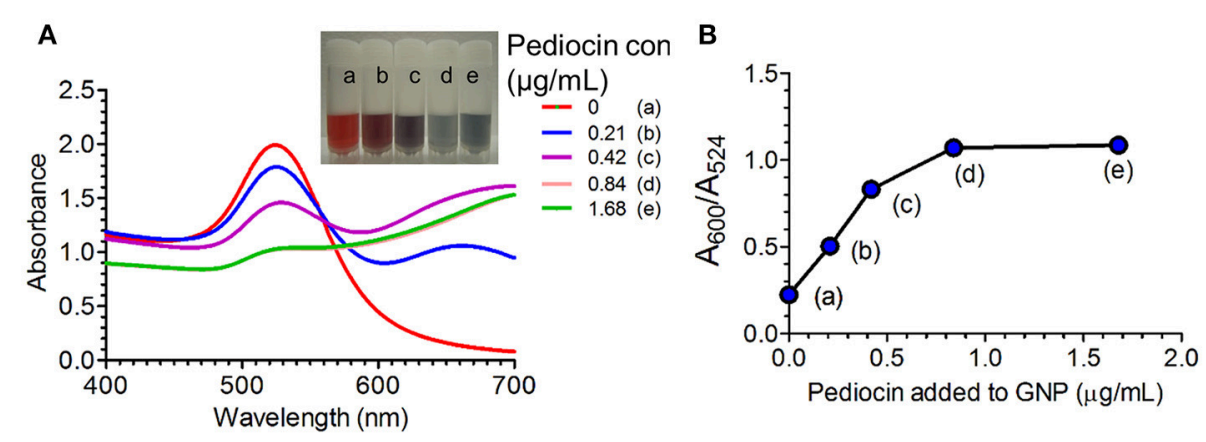

C

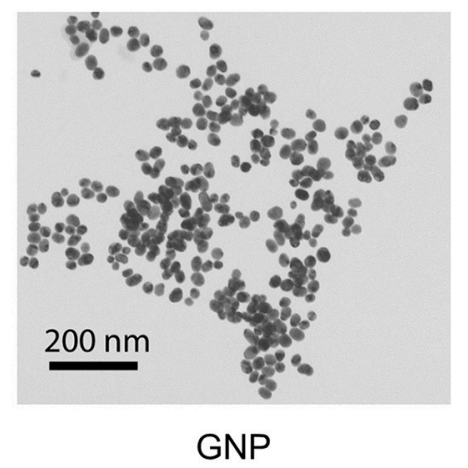

E

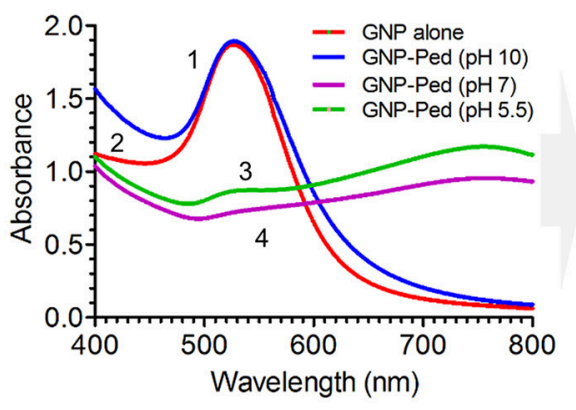

D

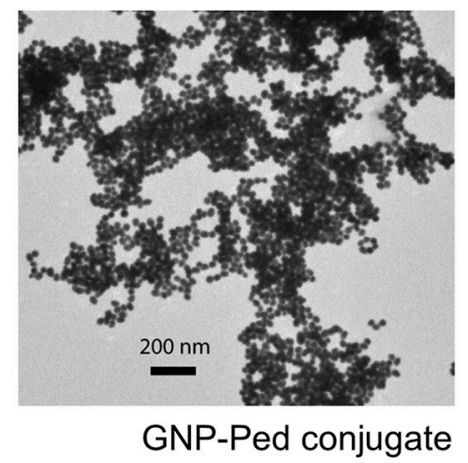

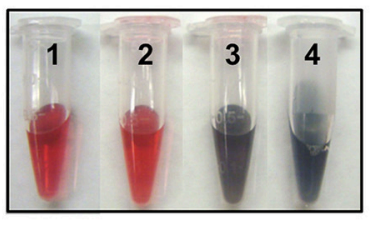

FIGURE 1 | Interaction of Pediocin AcH with gold nanoparticle (GNP). (A) Effect on the surface plasmon resonance (SPR) absorbance peak and color of GNP after interaction with different concentrations of Pediocin AcH. (B) The ratio of absorbance at $600 \mathrm{~nm}$ and $524 \mathrm{~nm}$ for GNP-Pediocin nanocomposite increased with the increasing concentrations of Pediocin AcH suggesting increased loading onto the gold nanoparticles. (C) TEM measurement of GNP revealed particle size to be $\sim 20 \mathrm{~nm}$. (D) TEM measurement of GNP after interaction with $1.68 \mu \mathrm{g} / \mathrm{ml}$ of Pediocin AcH demonstrating GNP-Pediocin conjugate size to be about $40 \mathrm{~nm}$.

(E) Quantitative and qualitative measurements demonstrating the effect of $\mathrm{pH}$ on the electrostatic interaction between the citrate-stabilized GNP and Pediocin.

GNP and the Pediocin. The GNP colloidal solution with $\mathrm{pH}$ 5.5 or GNP $\mathrm{pH}$ adjusted to 7 showed interaction with Pediocin $(0.8 \mu \mathrm{g} / \mathrm{mL})$ leading to a drop in $A_{\text {spr }}$ or $A_{524}$ intensity and produced violet color (Figure 1E). However, in the environment of GNP adjusted to $\mathrm{pH} 10$ caused Pediocin to have net negative charge since $\mathrm{pI}$ of Pediocin is 8.6 (BACTIBASE). Negatively charged Pediocin was unable to interact with the negatively charged GNP due to electrostatic repulsion, hence color did not change from red to violet (Figure 1E). These data suggest that GNP and Pediocin interact electrostatically. Next, we determined the amount of Pediocin and LAP loaded onto the GNP using bacterial inhibition and immunoblot assays.

\section{Functionalized GNP Reveals Enhanced Antilisterial Activity}

Functionalization/loading of GNP with Pediocin was ascertained by measuring the zone of inhibition (ZOI) of L. monocytogenes lawn on an agar plate. Comparing the diameter of ZOI of unconjugated Pediocin and gold-conjugated Pediocin, it was estimated that $1.0 \mu \mathrm{g}$ of Pediocin was bound to $1 \mathrm{~mL}$ of $1.5 \mathrm{nM}$ GNP when $1.25 \mu \mathrm{g}$ Pediocin was added (Figures 2A, B). TEM imaging also confirmed binding of GNP-Pediocin on the surface of $L$. monocytogenes (Figure $\mathbf{2 C}$, panel 2), whereas GNP alone was observed to form some aggregates with $L$. monocytogenes cells (Figure 2C, panel 1). Recombinant LAP (104 $\mathrm{kDa}$ ) overexpressed in E. coli was purified by Ni-ion affinity 
chromatography, and its purity was assessed by SDS-PAGE and Western blot (Figure 2D). Binding of LAP to the GNP was assayed by immunoblot assay using LAP-specific monoclonal antibody (Figure 2E). Immunoblot indicated the presence of the LAP-specific band in the GNP-LAP and GNP-PediocinLAP conjugates when $10 \mu \mathrm{g}$ of LAP was used. Quantification of the LAP bands demonstrated that 77.1 and $81.7 \%$ LAP was bound to GNP and GNP-Pediocin nanoconjugate, respectively (Figure 2F). This suggests $4.6 \%$ higher loading of LAP to the GNP in the presence of Pediocin.

Bacterial growth inhibition assay was performed to assess the antilisterial activity of the GNP-Pediocin and GNPPediocin-LAP nanoconjugates, which revealed a ZOI of 1.2$1.6 \mathrm{~mm}$ and $1.4-1.8 \mathrm{~mm}$, respectively against all tested Listeria species (Figures 3A,B). GNP-Pediocin and GNP-PediocinLAP showed $0.3-0.4 \mathrm{~cm}$ higher ZOI against the pathogenic Listeria spp. (L. monocytogenes and L. ivanovii) compared to non-pathogenic L. grayi, L. ivanovii, $L$. marthii, and $L$. welshimeri (Figures 3A,B). Interestingly, when GNP-Pediocin nanoconjugate was functionalized with LAP $(7.7 \mu \mathrm{g} / \mathrm{mL})$, the antilisterial activity of GNP-Pediocin-LAP nanoconjugate increased by $0.2 \mathrm{~cm}$ against all tested Listeria spp. (Figures 3A,B). Antilisterial activity of Pediocin alone was higher $(0.1-0.2 \mathrm{~cm})$ than the GNP-Pediocin conjugate (Figure S1A). Neither GNP nor LAP alone showed any antilisterial activity (Figure S1B). This loss in GNP-Pediocin antilisterial activity compared to pediocin alone can be accounted for the loss of free (unbound) Pediocin molecule during centrifugation after conjugation with GNP. The increased antilisterial activity of GNP-PediocinLAP could be attributed to the increased interaction of nanoconjugates via LAP with Listeria cell surface receptors for enhanced interaction and consequent inhibition by Pediocin. To further prove the involvement of LAP molecule in enhancing the antilisterial activity of GNP-Pediocin conjugate, we blocked conjugated LAP with the LAP-specific antibody. Bioassay data indicate that antilisterial activity of GNP-Ped-LAP was significantly diminished $(P<0.05)$ when LAP molecules were blocked with the anti-LAP antibody (Figure 3C, Figure S2).

\section{Gold Nanoconjugates Are Nontoxic and Inhibit Listeria Adhesion to Caco-2 Cells}

Though the nanoconjugates were designed to inactivate Listeria on food contact or noncontact surfaces, there is a potential for incidental exposure of nanoconjugates to food. Therefore, we performed a LDH assay to assess toxicity concerns that may be associated with GNP usage. Treatment of Caco-2 cell line with GNP, gold nanoconjugates (GNP-Pediocin, GNP-LAP, GNPPediocin-LAP), and free Pediocin and LAP showed less than $1 \%(0.65-0.99 \%)$ cytotoxicity while L. monocytogenes showed a very high cytotoxicity (64.03\%) after $1 \mathrm{~h}$ exposure (Figure 4A). Additional incubation of the monolayers with the GNPs and nanoconjugates for up to $24 \mathrm{~h}$ did not result in any increase in toxicity (data not shown). Protective attributes of GNP and nanoconjugates were also assessed by measuring the LDH release. Caco-2 cells were first exposed to GNP, GNP nanoconjugates, Pediocin and LAP, and then infected with L. monocytogenes.
Results from these experiments suggest that infection of Caco2 cells with $L$. monocytogenes alone caused $64.03 \pm 0.68 \%$ cytotoxicity. Whereas, pre-exposure of Caco-2 cells with GNP, GNP nanoconjugates, Pediocin or LAP alone significantly $(P$ $<0.0001)$ reduced $L$. monocytogenes-induced cytotoxicity from $64 \%$ to $4-7 \%$ (Figure $4 \mathrm{~A}$ ). The ability of the nanoconjugates to inhibit L. monocytogenes colonization of the epithelial monolayer possibly reduced cytotoxicity.

We also assessed the anti-infective nature of gold nanoconjugates by analyzing $L$. monocytogenes adhesion to Caco-2 cells that were pre-treated with free Pediocin, and LAP, GNP-Pediocin, GNP-LAP, and GNP-Pediocin-LAP. The $L$. monocytogenes counts were reduced from $5.65 \log _{10} \mathrm{CFU} / \mathrm{mL}$ to $5.15 \log _{10} \mathrm{CFU} / \mathrm{mL}$ when pre-treated with Pediocin, 4.56 $\log _{10} \mathrm{CFU} / \mathrm{mL}$ when pre-treated with LAP, $4.75 \log _{10} \mathrm{CFU} / \mathrm{mL}$ when pre-treated with GNP-Pediocin, $3.97 \log _{10} \mathrm{CFU} / \mathrm{mL}$ when pre-treated with GNP-LAP, and $3.49 \log _{10} \mathrm{CFU} / \mathrm{mL}$ when pre-treated with GNP-Pediocin-LAP (Figure 4B). These data clearly show that GNP-Pediocin complex functionalized with LAP had significantly higher $(P<0.001)$ inhibitory effect against L. monocytogenes adhesion to Caco-2 cells and this is possibly due to preoccupation of epithelial cell receptor, Hsp60 (Wampler et al., 2004; Burkholder and Bhunia, 2010) by GNP-Pediocin-LAP conjugate, thus prevented L. monocytogenes adhesion (Figure 4B). Altogether, these data suggest that gold nanoconjugates are nontoxic and show potential for preventing L. monocytogenes interaction with intestinal cells if the nanoconjugates were inadvertently ingested with food.

\section{Antibiofilm Activity of Gold Nanoconjugates}

\section{Nanoconjugates Prevented Biofilm Formation}

To test the ability of nanoconjugates to prevent $L$. monocytogenes biofilm formation, microtiter plate wells were seeded with bacteria and nanoconjugates simultaneously and incubated for $24 \mathrm{~h}$ to $48 \mathrm{~h}$. GNP-Pediocin-LAP treatment for $24 \mathrm{~h}$ resulted in a significant $(P<0.01)$ decrease in biofilm-forming $L$. monocytogenes cells $\left(6.25 \log _{10} \mathrm{CFU} / \mathrm{mL}\right)$ to $4 \log _{10} \mathrm{CFU} / \mathrm{mL}$ compared to GNP-Pediocin treatment, which resulted in a cell population of $5.15 \log _{10} \mathrm{CFU} / \mathrm{mL}$ in the biofilm (Figure 5A). This difference in anti-biofilm activity of GNP-Pediocin and GNPPediocin-LAP was more significant $(P<0.001)$ after $48 \mathrm{~h}$ of post-treatment, when biofilm cells $\left(7.45 \log _{10} \mathrm{CFU} / \mathrm{mL}\right)$ reduced to $4.48 \log _{10} \mathrm{CFU} / \mathrm{mL}$ and $2.7 \log _{10} \mathrm{CFU} / \mathrm{mL}$, respectively (Figure 5A). These data suggest $1.78 \log _{10} \mathrm{CFU} / \mathrm{mL}$ higher reduction in $L$. monocytogenes counts due to the co-action of Pediocin and LAP when GNP-Pediocin-LAP was used as a biofilm inhibitor as opposed to the just GNP-Pediocin nanoconjugates.

\section{Nanoconjugates Inhibited Pre-formed Biofilms}

We also tested the ability of gold nanoconjugates to inactivate preformed L. monocytogenes biofilms after treatment for 24 and $48 \mathrm{~h}$. Treatment of biofilm cells $\left(7.27 \log _{10} \mathrm{CFU} / \mathrm{mL}\right)$ with GNP-Pediocin-LAP nanoconjugates resulted in a higher reduction $\left(4.15 \log _{10} \mathrm{CFU} / \mathrm{mL}\right)$ compared to the GNPPediocin nanoconjugate treatment $\left(5.92 \log _{10} \mathrm{CFU} / \mathrm{mL}\right)$ for 

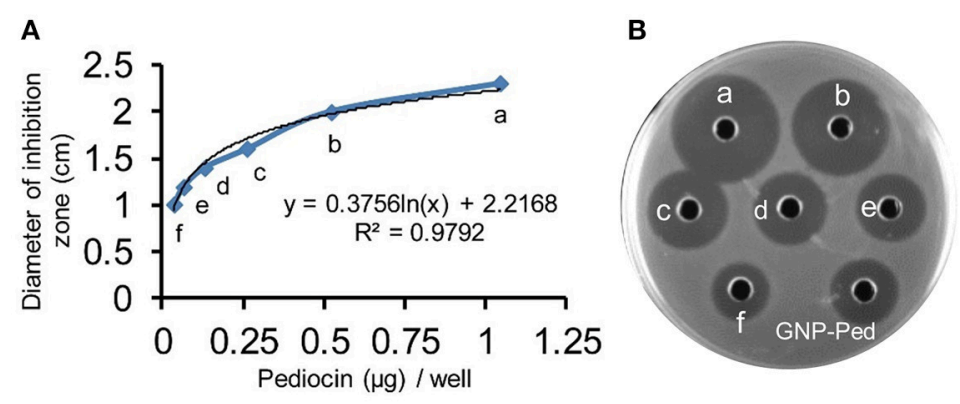

D

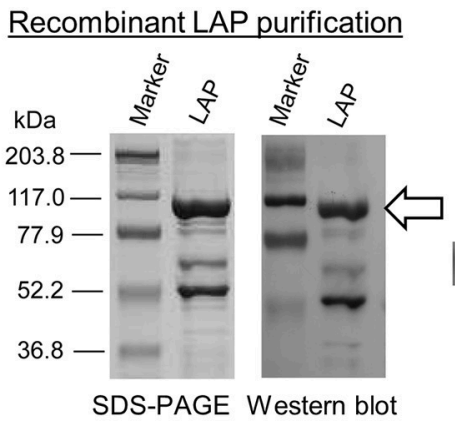

E

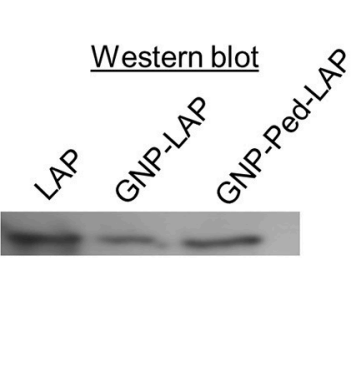

F
C

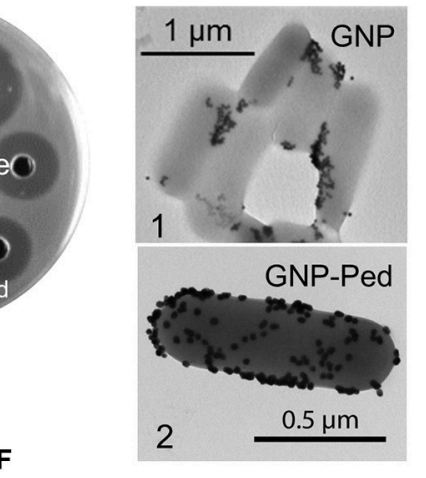

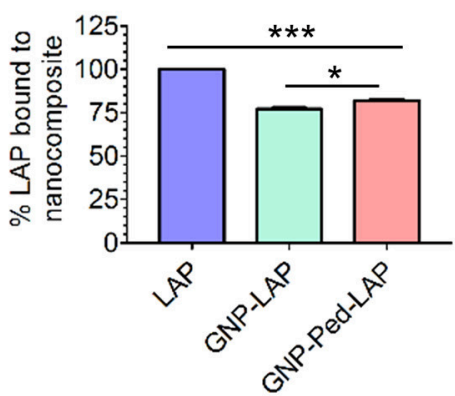

FIGURE 2 | Loading of Pediocin (Ped) and Listeria adhesion protein (LAP) on GNP. (A) The diameter of the zone of inhibition measured against indicator L. monocytogenes F4244 using known concentration of Pediocin in a bioassay on an agar plate (B) that helped in the estimation of Pediocin loaded on to GNP. Well labeled as GNP-Ped shows inhibition zone produced by Pediocin loaded on the GNP. (C) TEM shows the interaction of GNP (panel 1) and GNP-Pediocin nanoconjugate (panel 2) with L. monocytogenes cell. (D,E) SDS-PAGE and Western blot shows a single band of LAP molecule probed with a LAP-specific monoclonal antibody (indicated with arrow), which was quantified using ImageJ software $\mathbf{( F )}$ ). Data are average of three independent experiments analyzed in duplicate. ${ }^{\star \star \star} P<0.001 ;{ }^{*} P<0.05$.

$24 \mathrm{~h}$ (Figures 4, 5B). Interestingly, this difference in biofilm inactivation was even greater when the biofilm cells (7.27 $\log _{10} \mathrm{CFU} / \mathrm{mL}$ ) were exposed to gold nanoconjugates for $48 \mathrm{~h}$. Treatment of biofilms with GNP-Pediocin-LAP for $48 \mathrm{~h}$ resulted in a significant $(P<0.001)$ reduction in $L$. monocytogenes counts to $2.24 \log _{10} \mathrm{CFU} / \mathrm{mL}$ compared to just GNP-Pediocin treatment, which resulted in $4.71 \log _{10} \mathrm{CFU} / \mathrm{mL}$. However, no significant differences were observed between the prevention of biofilm formation (inhibition) and inactivation of pre-formed biofilm when treated with Pediocin, or GNP-Pediocin. GNP alone or GNP-LAP did not show any effect on the L. monocytogenes biofilms (Figure 5B). Collectively, these data show that GNPPediocin-LAP nanoconjugate possesses the highest antibiofilm activity than the other preparations tested in this study. Therefore, in surface decontamination experiments we used only GNP-Pediocin-LAP nanoconjugate to assess antilisterial activity.

\section{GNP-Pediocin-LAP Nanoconjugate Is Effective Surface Decontaminant}

The GNP-Pediocin-LAP nanoconjugates were applied on the agar surface and a conveyor belt system that were precontaminated with L. monocytogenes to test for surface decontamination efficacy. Spraying of GNP-Pediocin-LAP on $\mathrm{BHI}$ and MOX agar Petri plates pre-seeded with L. monocytogenes showed bactericidal effect (Figure 6A). The GNP-Pediocin-LAP showed $1.5 \log _{10} \mathrm{CFU} / \mathrm{mL}$ higher reduction $(P<0.001)$ in the $L$. monocytogenes counts (Figure 6A).

Further, we tested if GNP-Pediocin-LAP could decontaminate L. monocytogenes on an operational miniature conveyor system that was pre-contaminated with the bacterium to simulate an industrial setting (Figure 6B). Thirteen predetermined locations on the conveyor system were tested for the presence or absence of Listeria contamination before and after treatment with nanoconjugates. Data show GNP-Pediocin-LAP was able to decontaminate various parts of the conveyor system especially underneath the open bushing, rods, spokes of the gear, and big chain effectively that were positive for L. monocytogenes before gold nanoconjugate application (Figure 6B, Table 2). These data suggest that the GNP-Pediocin-LAP conjugate can be used as an effective surface decontaminant.

\section{DISCUSSION}

Application of colloidal metal solution, in particular, gold started with its use in enhancing light and electron microscopy, followed by its use in the development of sensitive immunoassays (Zhou et al., 2012). Surface plasmon resonance properties of gold colloidal solution offer qualitative visualization based on a color 


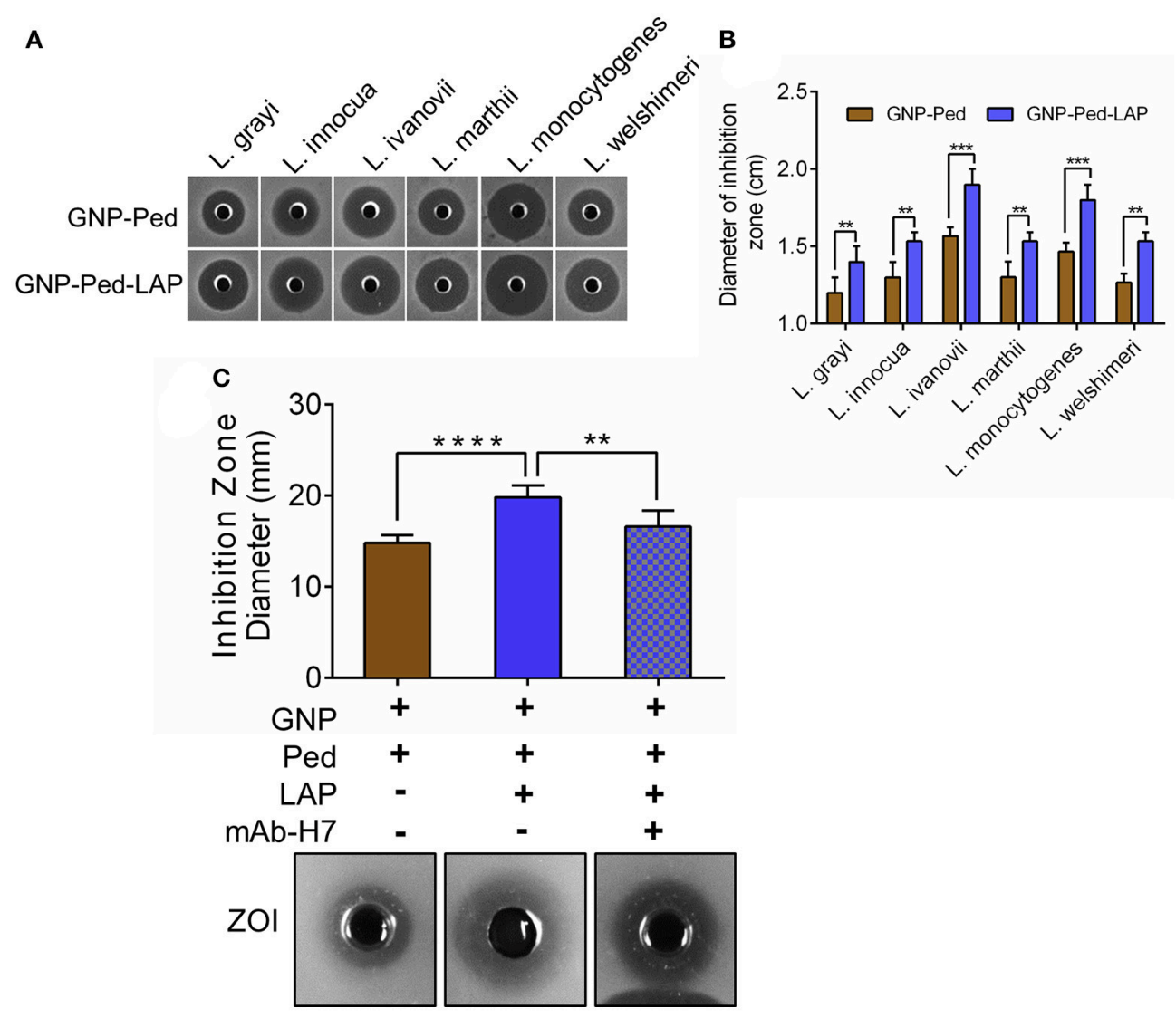

FIGURE 3 | Bioassay based assessment of antilisterial activity of GNP nanoconjugates. Qualitative (A) and quantitative (B) measurement of the diameter of the zone of inhibition (ZOI) caused by GNP-Pediocin and GNP-Pediocin-LAP nanoconjugates against Listeria species. (C) The anti-listerial activity of GNP-Pediocin-LAP nanoconjugates against $L$. monocytogenes after blocking with anti-LAP mAb-H7. Data are average of three independent experiments analyzed in duplicate. ${ }^{\star \star \star \star} P<$ $0.0001 ;{ }^{* \star *} P<0.001 ;{ }^{* \star} P<0.01$.
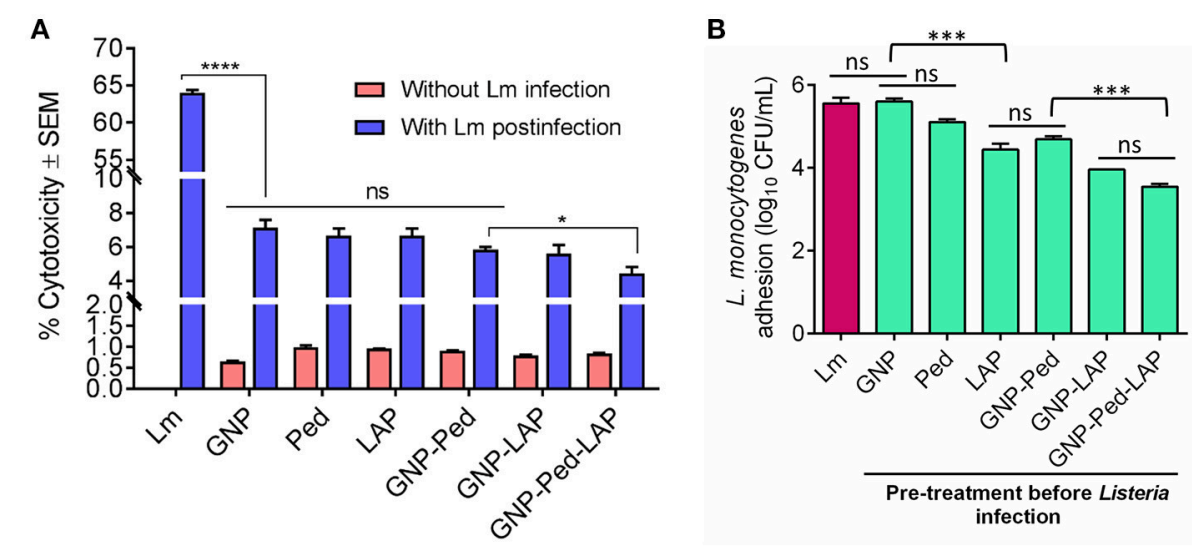

FIGURE 4 | In vitro assessment of cytotoxicity, preventive attributes, and anti-adhesion characteristics of gold nanocomposite with Caco-2 cell line. (A) Cytotoxicity was calculated by measuring the amount of lactate dehydrogenase (LDH) release from Caco-2 cells upon treatment with GNP, Pediocin (Ped) and LAP, GNP-Pediocin, GNP-LAP, GNP-Pediocin-LAP with or without L. monocytogenes infection. (B) Assessment of anti-adhesion attributes of GNP, and gold nanocomposites used in the cytotoxicity assay. Treatment of Caco-2 cells with $L$. monocytogenes $(L m)$ only was used a positive control. Data are average of three experiments analyzed in duplicate. ${ }^{* * *} P<0.0001 ;{ }^{* \star *} P<0.001 ;{ }^{*} P<0.05$; ns, no significance. 

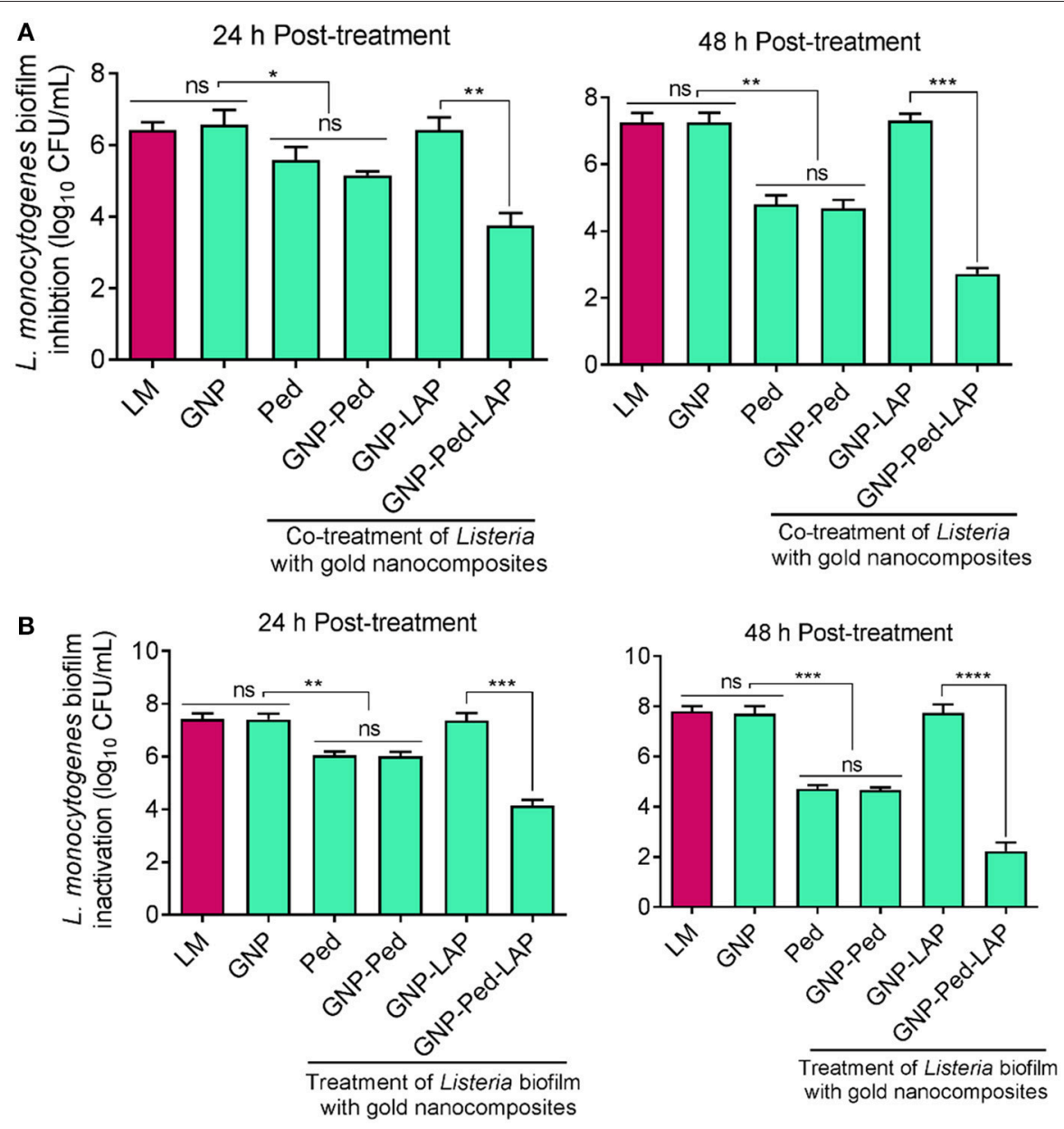

FIGURE 5 | Assessment of antibiofilm activity of gold nanoconjugates. (A) Prevention of $L$. monocytogenes biofilm formation using nanoconjugates. Both $L$. monocytogenes and gold nanoconjugates were inoculated simultaneously and Listeria growth in the biofilm was monitored at 24 and $48 \mathrm{~h}$. (B) Inactivation of $L$. monocytogenes cells in the pre-formed biofilm with nanoconjugates. L. monocytogenes cells were allowed to form biofilm for $24 \mathrm{~h}$ and then treated with gold nanoconjugates for $24 \mathrm{~h}$ and $48 \mathrm{~h}$ prior to $\mathrm{L}$. monocytogenes enumeration. Data are average of three experiments analyzed in triplicate. ${ }^{\star \star \star \star} P<0.0001 ;{ }^{\star \star \star} P<0.001$; ${ }^{\star *} P<0.01 ;{ }^{\star} P<0.05$; ns, no significance. Lm, Listeria monocytogenes; GNP, gold nanoparticle; Ped, Pediocin; LAP, Listeria adhesion protein.

change in colloidal solution (Thobhani et al., 2010). Colloidal gold solutions are used in the synthesis of the nanoparticle using various methods (Turkevich et al., 1951). The gold core provides stability to the assembly, while the citrate-capped gold nanoparticles provide tuneable surface property such as charge and hydrophobicity thus are suitable for stable conjugation and targeted delivery of various biomolecules in therapeutic and diagnostic applications (Khlebtsov et al., 2013).

In this study, we synthesized $20 \mathrm{~nm}$ citrate-capped anionic GNP and conjugated these with Pediocin, a bacteriocin with inhibitory activity against Gram-positive bacteria including $L$. monocytogenes (Bhunia et al., 1988, 1991) and LAP that reassociates back to the surface of L. monocytogenes cells after secretion (Burkholder et al., 2009; Jagadeesan et al., 2010). Thus, we created a smart and a stable nanocargo that can carry both specific recognition molecule and an antimicrobial peptide for enhanced antilisterial and antibiofilm activity for surface decontamination.
TEM confirmed the GNP to be about $20 \mathrm{~nm}$ and UV-vis spectroscopy measurement of surface plasmon resonance of the GNP indicated an electrostatic interaction between GNP and Pediocin (Brewer et al., 2005) (Figure 1). Due to the tunable surface property, GNP can interact with various biomolecules through different modes. It has been reported that the citratecapped GNP (ctGNP) interacts with bovine serum albumin (BSA) with electrostatic interactions forming a monolayer coating, whereas antibody can bind to ctGNP by displacing citrate ligands and bind with the nanoparticle metal core (Zhang et al., 2014). However, information on the delivery mechanism of the antimicrobial peptide at the cell surface of target bacteria are scarce, and thus open avenues for future studies that can provide more insights on the delivery mechanism and efficacies of target-specific peptide functionalized GNPs.

TEM analysis was performed to observe the interaction of GNP nanoconjugates with L. monocytogenes F4244 cells (Figure 2C). TEM images show the formation of GNP 

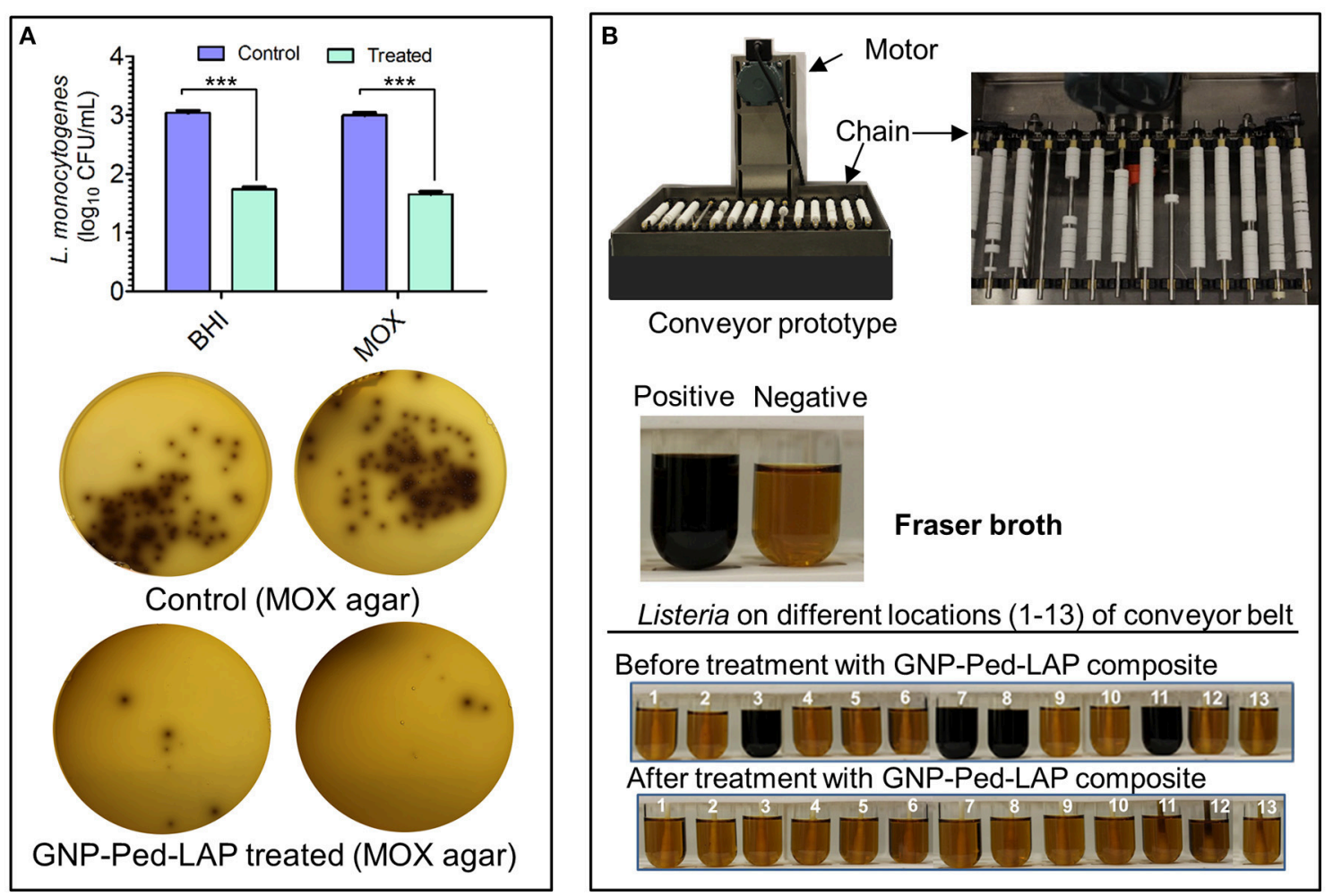

FIGURE 6 | Application of gold nanoconjugates as a surface decontaminant to inhibit L. monocytogenes. (A) The antilisterial activity of GNP-Pediocin-LAP nanoconjugates on the agar surface. Agar plates were first pre-seeded with bacteria and then treated with gold nanoconjugates. (B) Prototype conveyer belt system was used to assess the antilisterial activity of GNP-Pediocin-LAP nanoconjugates at various locations of the conveyor (see also Table 2). Fraser broth containing esculin and ferric ammonium citrate was used to observe the Listeria growth turning pale yellow media to black due to esculin hydrolase activity. Data are average of three independent experiments analyzed in triplicate. ${ }^{\star \star \star} \mathrm{P}<0.0001$. $\mathrm{BHI}$, brain heart infusion; MOX, modified Oxford agar.

aggregates during its interaction with L. monocytogenes cells (Figure 2C, panel 1). The purity of LAP biomolecule was assessed by using SDS-PAGE and Western blot with the LAP-specific antibody (Figure 2D), which revealed $104 \mathrm{kDa}$ band representing the full-length LAP (lmo1634 upper band). LAP consists of two enzymes, acetaldehyde dehydrogenase $(\mathrm{ALDH})$ and alcohol dehydrogenase $(\mathrm{ADH})$, called alcohol acetaldehyde dehydrogenase (Jagadeesan et al., 2010). The lower band $(\sim 50 \mathrm{kDa})$, which tends to separate from the $\mathrm{ADH}$ is acetaldehyde dehydrogenase (SDS-PAGE) and was confirmed to be LAP (lmo1634) with mass-spectrometry analysis (Drolia et al., 2018).

For the sustainable and green application of the antimicrobial agents, biocompatibility is the most important attribute that should be assessed before testing their antibacterial efficacies in the real-world scenario. Pediocin and LAP, GNP, GNPPediocin, and GNP-Pediocin-LAP used in this study did not exhibit any cytotoxic effect on the Caco-2 cell line (Figure 4A). It has been reported that typical mammalian cells carrying a net negative charge are more likely to interact with the cationic GNPs than anionic GNPs (Hauck et al., 2008; Lin et al., 2010). Therefore, positively charged GNPs has three times more membrane affinity and five times more internalization rate into cancer cells than the anionic GNP (Cho et al., 2009). Earlier studies also revealed that the positively charged GNP of $2 \mathrm{~nm}$ size possess antibacterial activity (Li et al., 2014). The anionic GNP synthesized in this study did not show any cytotoxic effect on the mammalian cells possibly due to electrostatic repulsion. Therefore, these gold nanoconjugates significantly reduced L. monocytogenes adhesion to Caco- 2 cells without causing any cytotoxic effects on the mammalian cells (Figures 4A,B).

Other advantages of the gold nanoconjugates are the large surface area that can carry a large payload and greater penetration/diffusion during the delivery of payloads (antimicrobials) (Pissuwan et al., 2010). Therefore, we tested the antilisterial and antibiofilm activity of GNP-Pediocin and GNP-Pediocin-LAP conjugates on Listeria species. Conjugation of Listeria-specific molecule, LAP significantly $(P<0.01)$ increased the antilisterial activity of GNP-Pediocin conjugate by $16.6-33.3 \%$ by increasing the zone of inhibition by 0.2 $0.4 \mathrm{~cm}$ compared to the zone of inhibition of $1.2 \mathrm{~mm}$ formed by the GNP-Pediocin (Figures 3A,B). This difference was even higher $(P<0.001)$, when GNP-Pediocin-LAP antilisterial activity was compared to GNP-Pediocin conjugates against pathogenic species, L. monocytogenes, and L. ivanovii. The greater 
antibacterial effect against these species can be attributed to the increased preferential interaction of LAP to the pathogenic Listeria (Jagadeesan et al., 2010) and consequent delivery of high antimicrobial payload at the surface of bacteria (Pissuwan et al., 2010) or slow release of Pediocin peptide at the surface of bacteria in the presence of LAP resulting in enhanced antilisterial activity. Pre-treatment of GNP-PediocinLAP nanoconjugate with anti-LAP mAb (Figure 3C) was able to partially block the LAP-mediated action highlighting the role of LAP in enhancing antilisterial activity of the smart nanoconjugates.

Biofilm formation is a natural tendency of a microbial cell growth or survival when it encounters a solid surface in an effort to compete effectively with other microbial cells for space and nutrient, and to resist any unfavorable environmental conditions (Stewart and Franklin, 2008; Flemming and Wingender, 2010). During biofilm formation, bacteria produce an extracellular polymeric substance (EPS) forming a three-dimensional biofilm scaffold on solid surfaces, which may be biotic (meat, fruits, oral cavity, etc.) or abiotic (floors, walls, drains, equipment, or food contact surfaces) (Flemming and Wingender, 2010). Biofilms are comprised of cultures of single species or mixed species with one being dominant. Advantages of microbial attachment and biofilm formation, on solid surfaces, are to provide some protection to the cells against desiccation, resistance to antibiotics or biocides (sanitizers), ultraviolet radiation, metallic cations, and physical removal of the cells by washing and cleaning. L. monocytogenes is one of the major biofilm-forming microorganisms of concern in the food industry (Galié et al., 2018; Gray et al., 2018), thus to find a solution, we have developed a smart gold nanoconjugate with enhanced antibiofilm activity against $L$. monocytogenes.

Higher penetration and/or diffusion of antilisterial gold nanoconjugates offers a greater advantage to the antimicrobial agent as the microorganisms in the biofilm enjoy the protection of self-produced EPS matrix, which renders antimicrobials ineffective due to enzymatic activity, inhibitors, and diffusion constraints (Flemming and Wingender, 2010). In this study, we observed higher inhibition and inactivation of Listeria in the biofilm after treatment with GNP-Pediocin-LAP compared to the GNP-Pediocin at $24 \mathrm{~h}$ and $48 \mathrm{~h}$ post-treatment (Figures 5A,B). This difference in the antilisterial antibiofilm activity of GNPPediocin-LAP could be attributed to specific interaction and slow release of Pediocin at the surface of bacteria due to the presence of LAP.

We also examined the potential application of GNP-PediocinLAP nanoconjugates for surface decontamination. First, spraying of gold nanoconjugate mist on the agar plate pre-seeded with Listeria revealed a high antilisterial activity at the agar surface (Figure 6A). Then, we applied the same GNP-PediocinLAP nanoconjugate spray on a fully operational miniature conveyor system simulating actual industrial conveyor belt that was pre-contaminated with Listeria (Figure 6B). The gold nanoconjugates successfully decontaminated the surface especially the locations such as underneath closed bushing, rods, spokes of the gear, and the big driving chain which can potentially harbor the pathogens. These data strongly suggest the possible use of the GNP-Pediocin-LAP as smart gold nanoconjugate for targeted decontamination of Listeria in a food processing plant, either on food contact or non-food contact surface where Listeria may persist.

In conclusion, a highly effective GNP-Pediocin-LAP conjugate consisting of Pediocin as an antimicrobial agent, and LAP, as a Listeria-specific ligand molecule was synthesized, characterized and tested for its ability to inactivate $L$. monocytogenes in biofilm and on the conveyor system as a surface decontaminant. Gold nanoconjugates were non-toxic and significantly reduced $L$. monocytogenes adhesion to mammalian cells. Listeria spp. inactivation bioassay demonstrated 16-33\% higher antilisterial activity of GNP-Pediocin-LAP conjugate compared to the GNP-Pediocin conjugate (Figures 3A,B). Results from this study also underscore that GNP-PediocinLAP has $2.5 \log _{10}$ higher antimicrobial activity against $L$. monocytogenes biofilm compared to the GNP-Pediocin conjugate. The outcome from the surface decontamination experiments performed on agar surface and model conveyor system emphasize the effectiveness of this novel GNP-PediocinLAP conjugate for possible application in industrial or food production/processing settings where Listeria could be a problem.

\section{AUTHOR CONTRIBUTIONS}

AS and AB: Conceived the idea and hypothesis; AS, MA, and $\mathrm{AB}$ : designed the experiments; $\mathrm{AS}, \mathrm{XB}$, and $\mathrm{MA}$ : performed the experiments; $\mathrm{AS}, \mathrm{XB}$, and $\mathrm{AB}$ : analyzed the data; $\mathrm{AB}$ : contributed the reagents, materials, analysis tools; $\mathrm{AS}$ and $\mathrm{AB}$ : Wrote the manuscript.

\section{FUNDING}

This research was supported in part by the National Academy of Science (US-AID) Award No. AID-263-A-15-00002 and the Agricultural Research Service of the US Department of Agriculture, under Agreement No. 59-8072-6-001, and any opinions, findings, conclusion, or recommendations expressed in this publication are those of the author(s) and do not necessarily reflect the view of the U.S. Department of Agriculture, USAID or NAS.

\section{SUPPLEMENTARY MATERIAL}

The Supplementary Material for this article can be found online at: https://www.frontiersin.org/articles/10.3389/fsufs. 2018.00074/full\#supplementary-material

Figure S1 | (A)The antilisterial activity of Pediocin (Ped) alone and GNP-Pediocin (GNP-Ped) conjugate against Listeria species. Numerical insets are the diameter of the zone of inhibition in centimeter (ZOI). (B) Purified LAP alone (well no. 1) and GNP alone (well no. 2) did not show any inhibition of $L$. monocytogenes.

Figure S2 | The anti-listerial activity of GNP-Pediocin-LAP nanoconjugates after blocking with anti-LAP mAb-H7 measured as the diameter of the zone of inhibition $(\mathrm{mm})$ from three independent experiments. 


\section{REFERENCES}

Allam, M., Tau, N., Smouse, S. L., Mtshali, P. S., Mnyameni, F., Khumalo, Z. T., et al. (2018). Whole-genome sequences of Listeria monocytogenes sequence type 6 isolates associated with a large foodborne outbreak in South Africa, 2017 to 2018. Genome Announc. 6, e00538-e00518. doi: 10.1128/genomeA.00538-18

Amalaradjou, M. A. R., and Venkitanarayanan, K. (2014). Antibiofilm effect of octenidine hydrochloride on Staphylococcus aureus, MRSA and VRSA. Pathogens 3, 404-416. doi: 10.3390/pathogens3020404

Bhunia, A. K., Johnson, M. C., and Ray, B. (1988). Purification, characterization and antimicrobial spectrum of a bacteriocin produced by Pediococcus acidilactici. J. Appl. Bacteriol. 65, 261-268. doi: 10.1111/j.1365-2672.1988.tb01893.x

Bhunia, A. K., Johnson, M. C., Ray, B., and Kalchayanand, N. (1991). Mode of action of pediocin AcH from Pediococcus acidilactici $\mathrm{H}$ on sensitive bacterial strains. J. Appl. Bacteriol. 70, 25-33. doi: 10.1111/j.1365-2672.1991.tb03782.x

Bonsaglia, E. C. R., Silva, N. C. C., Fernades, A., Araujo, J. P., Tsunemi, M. H., and Rall, V. L. M. (2014). Production of biofilm by Listeria monocytogenes in different materials and temperatures. Food Control 35, 386-391. doi: 10.1016/j.foodcont.2013.07.023

Brewer, S. H., Glomm, W. R., Johnson, M. C., Knag, M. K., and Franzen, S. (2005). Probing BSA binding to citrate-coated gold nanoparticles and surfaces. Langmuir 21, 9303-9307. doi: 10.1021/la050588t

Brust, M., Walker, M., Bethell, D., Schiffrin, D. J., and Whyman, R. (1994). Synthesis of thiol-derivatised gold nanoparticles in a twophase liquid-liquid system. J. Chem. Soc. Chem. Comm. 1994, 801-802. doi: 10.1039/C39940000801

Buchanan, R. L., Gorris, L. G., Hayman, M. M., Jackson, T. C., and Whiting, R. C. (2017). A review of Listeria monocytogenes: an update on outbreaks, virulence, dose-response, ecology, and risk assessments. Food Control 75, 1-13. doi: 10.1016/j.foodcont.2016.12.016

Burkholder, K. M., and Bhunia, A. K. (2010). Listeria monocytogenes uses Listeria adhesion protein (LAP) to promote bacterial transepithelial translocation, and induces expression of LAP receptor Hsp60. Infect. Immun. 78, 5062-5073. doi: 10.1128/IAI.00516-10

Burkholder, K. M., Kim, K.-P., Mishra, K., Medina, S., Hahm, B.-K., Kim, H., et al. (2009). Expression of LAP, a SecA2-dependent secretory protein, is induced under anaerobic environment. Microbes Infect. 11, 859-867. doi: 10.1016/j.micinf.2009.05.006

Chen, Y. I., Burall, L. S., Macarisin, D., Pouillot, R., Strain, E., De Jesus, A. J., et al. (2016). Prevalence and level of Listeria monocytogenes in ice cream linked to a listeriosis outbreak in the United States. J. Food Prot. 79, 1828-1832. doi: 10.4315/0362-028X.JFP-16-208

Cho, E. C., Xie, J., Wurm, P. A., and Xia, Y. (2009). Understanding the role of surface charges in cellular adsorption versus internalization by selectively removing gold nanoparticles on the cell surface with a I2/KI etchant. Nano Lett. 9, 1080-1084. doi: 10.1021/nl803487r

De La Rica, R., and Stevens, M. M. (2012). Plasmonic ELISA for the ultrasensitive detection of disease biomarkers with the naked eye. Nat. Nanotechnol. 7, 821-824. doi: 10.1038/nnano.2012.186

De Noordhout, C. M., Devleesschauwer, B., Angulo, F. J., Verbeke, G., Haagsma, J., Kirk, M., et al. (2014). The global burden of listeriosis: a systematic review and meta-analysis. Lancet Infect. Dis. 14, 1073-1082. doi: 10.1016/S1473-3099(14)70870-9

Drolia, R., Tenguria, S., Durkes, A. C., Turner, J. R., and Bhunia, A. K. (2018). Listeria adhesion protein induces intestinal epithelial barrier dysfunction for bacterial translocation. Cell Host Microbe 23, 470-484. doi: 10.1016/j.chom.2018.03.004

Faraday, M. (1857). X. The Bakerian lecture-experimental relations of gold (and other metals) to light. Philos. Trans. R. Soc. London 147, 145-181. doi: $10.1098 /$ rstl.1857.0011

Farber, J., Ross, W., and Harwig, J. (1996). Health risk assessment of Listeria monocytogenes in Canada. Int. J. Food Microbiol. 30, 145-156. doi: 10.1016/0168-1605(96)01107-5

Ferreira, V., Wiedmann, M., Teixeira, P., and Stasiewicz, M. J. (2014). Listeria monocytogenes persistence in food-associated environments: epidemiology, strain characteristics, and implications for public health. J. Food Prot. 77, 150-170. doi: 10.4315/0362-028X.JFP-13-150
Finelli, A., Gallant, C. V., Jarvi, K., and Burrows, L. L. (2003). Use of in-biofilm expression technology to identify genes involved in Pseudomonas aeruginosa biofilm development. J. Bacteriol. 185, 2700-2710. doi: $10.1128 / J B .185 .9 .2700-2710.2003$

Flemming, H.-C., and Wingender, J. (2010). The biofilm matrix. Nat. Rev. Microbiol. 8, 623-633. doi: 10.1038/nrmicro2415

Fu, Y., Deering, A. J., Bhunia, A. K., and Yao, Y. (2017). Pathogen biofilm formation on cantaloupe surface and its impact on the antibacterial effect of lauroyl arginate ethyl. Food Microbiol. 64, 139-144. doi: 10.1016/j.fm.2016.12.020

Galié, S., García-Gutiérrez, C., Miguélez, E. M., Villar, C. J., and Lombó, F. (2018). Biofilms in the food industry: Health aspects and control methods. Front. Microbiol. 9:898. doi: 10.3389/fmicb.2018.00898

Ghosh, P., Han, G., De, M., Kim, C. K., and Rotello, V. M. (2008). Gold nanoparticles in delivery applications. Adv. Drug Delivery Rev. 60, 1307-1315. doi: 10.1016/j.addr.2008.03.016

Graves, L. M., Helsel, L. O., Steigerwalt, A. G., Morey, R. E., Daneshvar, M. I., Roof, S. E., et al. (2010). Listeria marthii sp. nov., isolated from the natural environment, finger lakes national forest. Int. J. Syst. Evol. Microbiol. 60, 1280-1288. doi: 10.1099/ijs.0.014118-0

Gray, J. A., Chandry, P. S., Kaur, M., Kocharunchitt, C., Bowman, J. P., and Fox, E. M. (2018). Novel biocontrol methods for Listeria monocytogenes biofilms in food production facilities. Front. Microbiol. 9:605. doi: $10.3389 /$ fmicb. 2018.00605

Haiss, W., Thanh, N. T., Aveyard, J., and Fernig, D. G. (2007). Determination of size and concentration of gold nanoparticles from UV- Vis spectra. Anal. Chem. 79, 4215-4221. doi: 10.1021/ac0702084

Handford, C. E., Dean, M., Henchion, M., Spence, M., Elliott, C. T., and Campbell, K. (2014). Implications of nanotechnology for the agri-food industry: opportunities, benefits and risks. Trends Food Sci. Technol. 40, 226-241. doi: 10.1016/j.tifs.2014.09.007

Hauck, T. S., Ghazani, A. A., and Chan, W. C. W. (2008). Assessing the effect of surface chemistry on gold nanorod uptake, toxicity, and gene expression in mammalian cells. Small 4, 153-159. doi: 10.1002/smll.200700217

He, S., Guo, Z., Zhang, Y., Zhang, S., Wang, J., and Gu, N. (2007). Biosynthesis of gold nanoparticles using the bacteria Rhodopseudomonas capsulata. Mater. Lett. 61, 3984-3987. doi: 10.1016/j.matlet.2007.01.018

Ivanek, R., Gröhn, Y. T., Tauer, L. W., and Wiedmann, M. (2005). The cost and benefit of Listeria monocytogenes food safety measures. Crit. Rev. Food Sci. Nutr. 44, 513-523. doi: 10.1080/10408690490489378

Jagadeesan, B., Fleishman Littlejohn, A. E., Amalaradjou, M. A.R., Singh, A. K., Mishra, K. K., Bhunia, A. K., et al. (2011). N-Terminal Gly $y_{24}$ - Gly 411 domain in Listeria adhesion protein interacts with host receptor Hsp60. PLoS ONE 6:e20694. doi: 10.1371/journal.pone.0020694

Jagadeesan, B., Koo, O. K., Kim, K. P., Burkholder, K. M., Mishra, K. K., Aroonnual, A., et al. (2010). LAP, an alcohol acetaldehyde dehydrogenase enzyme in Listeria promotes bacterial adhesion to enterocyte-like Caco-2 cells only in pathogenic species. Microbiology 156, 2782-2795. doi: 10.1099/mic.0.036 509-0

Jordan, K., and Mcauliffe, O. (2018). Listeria monocytogenes in foods. Adv. Food Nutr. Res. 86, 181-213. doi: 10.1016/bs.afnr.2018.02.006

Khlebtsov, N., Bogatyrev, V., Dykman, L., Khlebtsov, B., Staroverov, S., Shirokov, A., et al. (2013). Analytical and theranostic applications of gold nanoparticles and multifunctional nanocomposites. Theranostics 3, 167-180. doi: $10.7150 /$ thno. 5716

Kim, K. P., Jagadeesan, B., Burkholder, K. M., Jaradat, Z. W., Wampler, J. L., Lathrop, A. A., et al. (2006). Adhesion characteristics of Listeria adhesion protein (LAP)-expressing Escherichia coli to Caco-2 cells and of recombinant LAP to eukaryotic receptor $\mathrm{Hsp60}$ as examined in a surface plasmon resonance sensor. FEMS Microbiol. Lett. 256, 324-332. doi: 10.1111/j.1574-6968.2006.00140.x

Koo, O. K., Amalaradjou, M. A. R., and Bhunia, A. K. (2012). Recombinant probiotic expressing Listeria adhesion protein attenuates Listeria monocytogenes virulence in vitro. PLoS ONE 7:e29277. doi: 10.1371/journal.pone.0029277

Kumar, S., Aaron, J., and Sokolov, K. (2008). Directional conjugation of antibodies to nanoparticles for synthesis of multiplexed optical contrast agents with both delivery and targeting moieties. Nat. Protocols 3, 314-320. doi: $10.1038 /$ nprot.2008.1 
Kurniawan, F., Tsakova, V., and Mirsky, V. M. (2006). Gold nanoparticles in nonenzymatic electrochemical detection of sugars. Electroanalysis 18, 1937-1942. doi: 10.1002/elan.200603607

Larsen, H. E., and Seeliger, H. P. R. (1966). A Mannitol Fermenting Listeria: Listeria grayi sp. $n$. Bilthoven/Holland, 35-39.

Li, X., Robinson, S. M., Gupta, A., Saha, K., Jiang, Z., Moyano, D. F., et al. (2014). Functional gold nanoparticles as potent antimicrobial agents against multidrug-resistant bacteria. ACS Nano 8, 10682-10686. doi: 10.1021/nn5042625

Lin, J., Zhang, H., Chen, Z., and Zheng, Y. (2010). Penetration of lipid membranes by gold nanoparticles: insights into cellular uptake, cytotoxicity, and their relationship. ACS Nano 4, 5421-5429. doi: 10.1021/nn1010792

Mccollum, J. T., Cronquist, A. B., Silk, B. J., Jackson, K. A., O'connor, K. A., Cosgrove, S., et al. (2013). Multistate outbreak of listeriosis associated with cantaloupe. New Eng. J. Med. 369, 944-953. doi: 10.1056/NEJMoa1215837

Mihindukulasuriya, S., and Lim, L.-T. (2014). Nanotechnology development in food packaging: a review. Trends Food Sci. Technol. 40, 149-167. doi: 10.1016/j.tifs.2014.09.009

Mukherjee, P., Senapati, S., Mandal, D., Ahmad, A., Khan, M. I., Kumar, R., et al. (2002). Extracellular synthesis of gold nanoparticles by the fungus Fusarium oxysporum. ChemBioChem 3, 461-463. doi: 10.1002/1439-7633(20020503)3:5\&lt;461::AID-CBIC461\&gt;3.0.CO;2-X

Pan, Y., Breidt, F., and Kathariou, S. (2006). Resistance of Listeria monocytogenes biofilms to sanitizing agents in a simulated food processing environment. Appl. Environ. Microbiol. 72, 7711-7717. doi: 10.1128/AEM.01065-06

Pandiripally, V. K., Westbrook, D. G., Sunki, G. R., and Bhunia, A. K. (1999). Surface protein p104 is involved in adhesion of Listeria monocytogenes to human intestinal cell line, Caco-2. J. Med. Microbiol. 48, 117-124. doi: 10.1099/00222615-48-2-117

Peer, D., Karp, J. M., Hong, S., Farokhzad, O. C., Margalit, R., and Langer, R. (2007). Nanocarriers as an emerging platform for cancer therapy. Nat. Nanotechnol. 2, 751-760. doi: 10.1038/nnano.2007.387

Pissuwan, D., Cortie, C. H., Valenzuela, S. M., and Cortie, M. B. (2010). Functionalised gold nanoparticles for controlling pathogenic bacteria. Trends Biotechnol. 28, 207-213. doi: 10.1016/j.tibtech.2009.12.004

Pouillot, R., Klontz, K. C., Chen, Y., Burall, L. S., Macarisin, D., Doyle, M., et al. (2016). Infectious dose of Listeria monocytogenes in outbreak linked to ice cream, United States, 2015. Emerging Infect. Dis. 22, 2113-2119. doi: 10.3201/eid2212.160165

Rangnekar, A., Sarma, T. K., Singh, A. K., Deka, J., Ramesh, A., and Chattopadhyay, A. (2007). Retention of enzymatic activity of alpha-amylase in the reductive synthesis of gold nanoparticles. Langmuir 23, 5700-5706. doi: $10.1021 / \mathrm{la} 062749 \mathrm{e}$

Roberts, P. H., Davis, K. C., Garstka, W. R., and Bhunia, A. K. (2001). Lactate dehydrogenase release assay from Vero cells to distinguish verotoxin producing Escherichia coli from non-verotoxin producing strains. J. Microbiol. Methods 43, 171-181. doi: 10.1016/S0167-7012(00)00222-0

Rocourt, J., Boerlin, P., Grimont, F., Jacquet, C., and Piffaretti, J.-C. (1992). Assignment of Listeria grayi and Listeria murrayi to a single species, Listeria grayi, with a revised description of Listeria grayi. Int. J. Syst. Evol. Microbiol. 42, 171-174. doi: 10.1099/00207713-42-1-171

Rocourt, J., and Grimont, P. A. (1983). Listeria welshimeri sp. nov. and Listeria seeligeri sp. nov. Int. J. Syst. Evol. Microbiol. 33, 866-869.

Rossi, M., Cubadda, F., Dini, L., Terranova, M., Aureli, F., Sorbo, A., et al. (2014). Scientific basis of nanotechnology, implications for the food sector and future trends. Trends Food Sci. Technol. 40, 127-148. doi: 10.1016/j.tifs.2014.09.004

Saha, K., Agasti, S. S., Kim, C., Li, X., and Rotello, V. M. (2012). Gold nanoparticles in chemical and biological sensing. Chem. Rev. 112, 2739-2779. doi: $10.1021 / \mathrm{cr} 2001178$

Scallan, E., Hoekstra, R. M., Angulo, F. J., Tauxe, R. V., Widdowson, M. A., Roy, S. L., et al. (2011). Foodborne illness acquired in the United States-major pathogens. Emerging Infect. Dis. 17, 7-15. doi: 10.3201/eid1701.P11101
Schneider, C. A., Rasband, W. S., and Eliceiri, K. W. (2012). NIH Image to ImageJ: 25 years of image analysis. Nat. Methods 9, 671-675. doi: 10.1038/ nmeth.2089

Schwartz, B., Hexter, D., Broome, C. V., Hightower, A. W., Hirschhorn, R. B., Porter, J. D., et al. (1989). Investigation of an outbreak of listeriosis: new hypotheses for the etiology of epidemic Listeria monocytogenes infections. J. Infect. Dis. 159, 680-685. doi: 10.1093/infdis/159.4.680

Seeliger, H. P., Rocourt, J., Schrettenbrunner, A., Grimont, P. A., and Jones, D. (1984). Listeria ivanovii sp. nov. Int. J. Syst. Evol. Microbiol. 34, 336-337.

Smith, M., Takeuchi, K., Anderson, G., Ware, G., Mcclure, H., Raybourne, R., et al. (2008). Dose-response model for Listeria monocytogenes-induced stillbirths in nonhuman primates. Infect. Immun. 76, 726-731. doi: 10.1128/IAI. 01366-06

Song, J. Y., Jang, H.-K., and Kim, B. S. (2009). Biological synthesis of gold nanoparticles using Magnolia kobus and Diopyros kaki leaf extracts. Process Biochem. 44, 1133-1138. doi: 10.1016/j.procbio.2009.06.005

Stewart, P. S., and Franklin, M. J. (2008). Physiological heterogeneity in biofilms. Nat. Rev. Microbiol. 6, 199-210. doi: 10.1038/nrmicro1838

Swaminathan, B., and Gerner-Smidt, P. (2007). The epidemiology of human listeriosis. Microbes Infect. 9, 1236-1243. doi: 10.1016/j.micinf.2007. 05.011

Thakkar, K. N., Mhatre, S. S., and Parikh, R. Y. (2010). Biological synthesis of metallic nanoparticles. Nanomed. Nanotechnol. Biol. Med. 6, 257-262. doi: 10.1016/j.nano.2009.07.002

Thobhani, S., Attree, S., Boyd, R., Kumarswami, N., Noble, J., Szymanski, M., et al. (2010). Bioconjugation and characterisation of gold colloid-labelled proteins. J. Immunol. Methods 356, 60-69. doi: 10.1016/j.jim.2010.02.007

Turkevich, J., Stevenson, P. C., and Hillier, J. (1951). A study of the nucleation and growth processes in the synthesis of colloidal gold. Discuss. Faraday Soc. 11, 55-75. doi: 10.1039/df9511100055

Wampler, J. L., Kim, K. P., Jaradat, Z., and Bhunia, A. K. (2004). Heat shock protein 60 acts as a receptor for the Listeria adhesion protein in Caco-2 cells. Infect. Immun. 72, 931-936. doi: 10.1128/IAI.72.2.931-936.2004

Wei, H., Li, B., Li, J., Wang, E., and Dong, S. (2007). Simple and sensitive aptamerbased colorimetric sensing of protein using unmodified gold nanoparticle probes. Chem. Comm. 2007, 3735-3737. doi: 10.1039/b707642h

Weidemaier, K., Carruthers, E., Curry, A., Kuroda, M., Fallows, E., Thomas, J., et al. (2015). Real-time pathogen monitoring during enrichment: a novel nanotechnology-based approach to food safety testing. Int. J. Food Microbiol. 198, 19-27. doi: 10.1016/j.ijfoodmicro.2014.12.018

Yang, R., Johnson, M. C., and Ray, B. (1992). Novel method to extract large amounts of bacteriocins from lactic acid bacteria. Appl. Environ. Microbiol. 58, 3355-3359.

Zhang, S., Moustafa, Y., and Huo, Q. (2014). Different interaction modes of biomolecules with citrate-capped gold nanoparticles. ACS Appl. Mater. Interfac. 6, 21184-21192. doi: 10.1021/am506112u

Zhou, G., Liu, Y., Luo, M., Xu, Q., Ji, X., and He, Z. (2012). Peptide-capped gold nanoparticle for colorimetric immunoassay of conjugated abscisic acid. ACS Appl. Mater. Interfac. 4, 5010-5015. doi: 10.1021/am301380q

Conflict of Interest Statement: The authors declare that the research was conducted in the absence of any commercial or financial relationships that could be construed as a potential conflict of interest.

Copyright (c) 2018 Singh, Bai, Amalaradjou and Bhunia. This is an open-access article distributed under the terms of the Creative Commons Attribution License (CC $B Y)$. The use, distribution or reproduction in other forums is permitted, provided the original author(s) and the copyright owner(s) are credited and that the original publication in this journal is cited, in accordance with accepted academic practice. No use, distribution or reproduction is permitted which does not comply with these terms. 